Article

\title{
Operation Algorithms and Computational Simulation of Physical Cooling and Heat Recovery for Indoor Space Conditioning. A Case Study for a Hydro Power Plant in Lugano, Switzerland
}

\author{
Dimitris Katsaprakakis ${ }^{1, *}$, Vasilis Kagiamis ${ }^{2}$, George Zidianakis ${ }^{1}$ and Luca Ambrosini ${ }^{3}$ \\ 1 Wind Energy and Power Plants Synthesis Laboratory, Department of Mechanical Engineering, \\ Hellenic Mediterranean University, Estavromenos, 71410 Heraklion Crete, Greece \\ 2 Xenikakis S.A., Knossos Av. Heraklion Crete, 71409 Crete, Greece \\ 3 Azienda Elettrica di Massagno (AEM) SA, 6900 Massagno, Switzerland \\ * Correspondence: dkatsap@staff.teicrete.gr; Tel.: +30-2810-379220
}

Received: 12 July 2019; Accepted: 20 August 2019; Published: 22 August 2019

\begin{abstract}
This article presents the computational simulation process and the operation algorithms of the VAV and VRV systems, for indoor space conditioning, with extensive physical cooling and heat recovery. Through the introduction of appropriate operation algorithms, the article aims to highlight the high energy saving potential on indoor space conditioning, by exploiting physical cooling and heat recovery processes. The proposed algorithms are evaluated with a case study for a hydro power plant building located in the area of Lugano, Switzerland, with significant cooling needs for the whole year, due to high internal heat gains from indoor electrical equipment. This fact enables physical cooling during winter, for the cooling load coverage, and heat recovery, for the concurrent heating load coverage in different thermal zones of the building. Analytical operation algorithms are developed for a VAV and a VRV system. Both algorithms are computationally simulated. With the VAV system, $86.1 \%$ and $63.7 \%$ of the annual cooling and heating demand, respectively are covered by physical cooling and heat recovery. With the VRV system, $58.5 \%$ of the annual heating demand is covered by heat recovery. The set-up cost of the VAV system is almost twice higher than the set-up cost of the VRV system.
\end{abstract}

Keywords: physical cooling; heat recovery; heating and cooling of buildings; variable air volume; variable refrigerant volume; energy saving; buildings energy performance; computational simulation

\section{Introduction}

\subsection{Physical Cooling and Heat Recovery}

Physical cooling is the process of indoor space cooling with fresh, cool air flow. It can be applied when the cooling loads exist while, at the same time, the ambient temperature remains lower than the required indoor space temperature, imposed by the thermal comfort requirements, as defined in the relevant directives. Such conditions are usually met in cases of high internal heat gains from devices or human beings (e.g., industrial buildings, conference rooms or theatres, etc.) or intensive heat gains from the direct penetration of solar radiation through transparent surfaces (e.g., in bioclimatic buildings with extensive transparent surfaces properly oriented). Physical cooling, as a simple and natural process, has been studied in former scientific articles, usually referred to as "economizer operation mode". Indicatively, the energy flow analysis with different technologies and systems' sizes and the evaluation of the achieved energy savings are investigated in [1], while different operation strategies 
for the involved economizer's dampers have been proposed in [2]. Alternative control methods of the variable air volume (VAV) systems operation, aiming at the minimisation of the energy consumption by exploiting the ventilation needs through the economizer constitutes another common research topic in the relevant literature [3,4]. A review article is available in [5], covering a wide range of topics related to the VAV systems: Most recent technologies on air flow control, simulation and modelling of the VAV systems, control strategies and optimization tools, faults detection and remedies. Finally, according to a comparison analysis of the VAV and variable refrigerant volume (VRV) systems, based on the simulation of their operation for a particular existing building particularly for the cooling season [6] or for the US climate conditions [7], a total energy saving from $27 \%$ to $58 \%$ seems to be feasible with the VRV system, compared to the VAV. The achieved energy saving percentage depends on the particular application configuration and the indoor space thermal comfort standards and outdoor climate conditions.

Heat recovery describes the exploitation process of the heat disposed from heat pumps, thermal generators, industrial wastes, etc., for the coverage of concurrent, or not, heating needs. Heat recovery constitutes a widely studied and investigated subject in the scientific literature. In short lines, indicatively, the following characteristic applications can be mentioned:

Industrial waste heat recovery

Most usually, thermal processes are involved in a wide range of industrial processes, through which considerable amounts of thermal energy are disposed. Precisely due to these large amounts of disposed thermal energy, often in high temperatures, implying corresponding high contained exergy, highly promising and feasible applications are based on industrial waste heat recovery [8-11]. Heat recovery processes have been traditionally popular in the steel and iron, food, plastics and ceramics industry. The most common application is the exploitation of the disposed heat from the thermal power plants in district heating systems [12]. Apart from district heating, more sophisticated applications have been also proposed (hydrogen production, food processing, etc. [13-15]).

Heat recovery for domestic applications

Another popular topic is heat recovery in domestic applications. In such cases, heat recovery is most commonly realized with the capture of the disposed thermal energy from heat pumps, during the cooling operation mode [16,17]. The recovered heat is usually exploited for the production of hot water, swimming pools heating, etc. [18]. Another popular application is heat recovery from waste water (drain water) [19-21]. Finally, among the scientific literature an article proposing a novel heat recovery system for a variable refrigerant flow (VRF) system is also presented in [22].

\subsection{Scope and Innovation of the Article}

The scope of this article is:

- to introduce an operation algorithm for a variable air volume (VAV) system, emphasizing on the maximisation of physical cooling and heat recovery.

- to indicate the corresponding calculation process.

- to make a comparison between a VAV and a VRV system, with regard to energy efficiency and economic aspects.

Currently, there are several works focused on the optimization of VAV or VRV systems operation, with regard to specific optimization parameters, such as the discharge air temperature [23], by applying genetic algorithms or artificial neural networks [24,25] or by focusing on the applied control algorithm of the involved air conditioning system [26]. Nevertheless, none of them focuses on the development of an optimized operation algorithm on physical cooling and heat recovery, which is the particular subject of the current article. Consequently, there is also no integrated calculation process so far presented, based on the computational simulation through the realization of any specific operation algorithm. 
The same lack is also traced on the comparison of the VAV and VRV systems aiming at high energy savings through physical cooling and heat recovery. These issues are foreseen as the main innovation contribution of this article.

The above are realized with a case study for a hydro power plant building operated by Azienda Elettrica di Massagno SA (AEM SA), in Lugano, Switzerland. The existence of significant cooling load in a specific space at the building's basement for the whole year due to internal heat gains from machinery and equipment and the simultaneous heating load of the building's ground and first floors in winter offer the essential prerequisites for:

- The physical cooling of the basement room during most time of the year, with ambient available temperatures lower than the desirable temperature in this room;

- The concurrent heating of the ground and first floors during winter, based on the disposed heat recovery due to the cooling of the basement room.

The above requirements for indoor space concurrent heating and cooling offer an excellent case for the implementation of the proposed work and its formulation as a reference case study on the specific scientific and technical topic. With the implementation of this study, the high energy saving potential achieved with physical cooling and heat recovery will be revealed.

\section{Data Regarding the under Consideration Building}

\subsection{Building's Location, Geometry and Thermophysical Features}

The under consideration hydro power plant is located approximately $5.1 \mathrm{~km}$ north from the centre of the city of Lugano, in south Switzerland, at a position with an absolute altitude at $345 \mathrm{~m}$. The building consists of three levels in total, one basement (level -1), the ground floor (level 0) and the first floor (level 1). The building is fully detached.

For the needs of the heating and cooling load calculation, the building is divided in three thermal zones, based on the indoor space usage and the required temperature and relative humidity in each one of them. The thermal zone 1 contains the electrical and electronic equipment room at the basement (covered area $135 \mathrm{~m}^{2}$, space volume $270 \mathrm{~m}^{3}$ ), while thermal zone 2 contains all the offices, the shared spaces and, generally, all the other indoor conditioned space, apart from the basement (covered area $427 \mathrm{~m}^{2}$, space volume $1535 \mathrm{~m}^{3}$ ). The thermal zone 3 contains all the non-conditioned spaces.

The U-factor for the building's envelope opaque surfaces (roof and vertical walls) was calculated at $2.97 \mathrm{~W} / \mathrm{m}^{2} \mathrm{~K}$ (reinforced concrete, roughcast in both sides), given the lack of any type of insulation, according to the description and the data on the building's constructive features provided by the management of the hydro power plant. For the building's windows, (single glazing, aluminum frame without thermal brake) the U-factor was adopted equal to $5.8 \mathrm{~W} / \mathrm{m}^{2} \mathrm{~K}$. The solar gain factor for the single glazing windows was assumed equal to 0.87 .

\subsection{Meteorological Data}

The annual time series of the hourly average values of the Global Horizontal Irradiance (GHI), the ambient temperature, the relative humidity and the wind velocity were developed based on the monthly average data published by the Federal Office of Meteorology and Climatology MeteoSwiss [27] for the area of Lugano, and statistical data for similar continental climates in northern Greece (Region of Macedonia) available by the authors. The developed time series for the above-mentioned magnitudes are presented in Figure 1. 

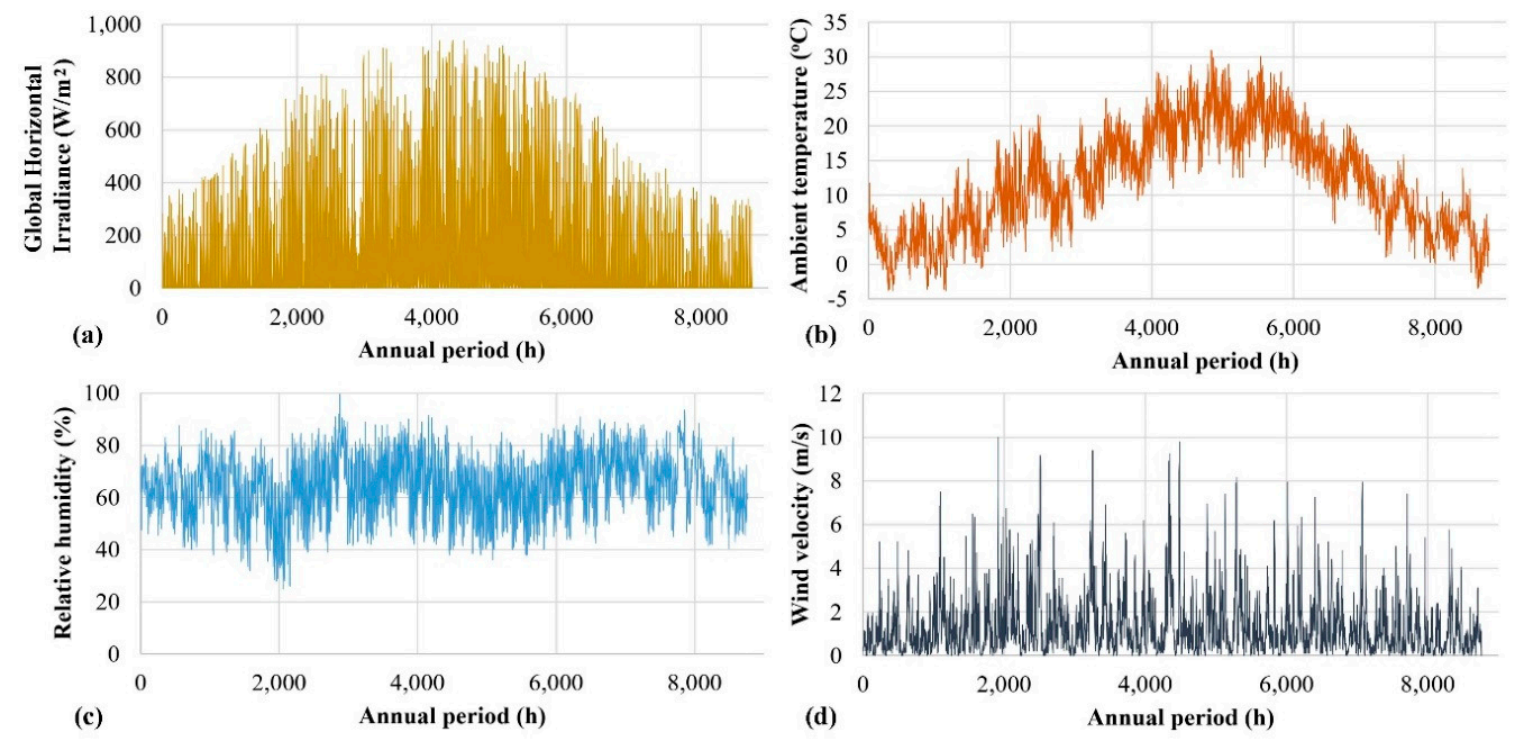

Figure 1. Annual time series of (a) global horizontal irradiance; (b) ambient temperature; (c) ambient relative humidity, and (d) wind velocity.

\subsection{Heating and Cooling Load Calculation}

The heating and cooling load calculation of the under examination building is executed according to the fundamental heat transfer theory, as it is applied by ASHRAE and the overall approach for the heat transfer and solar gains calculation in buildings [28-30]. The calculation was executed with the TRNSYS application. The building's simulation model and the logical diagram introduced in the software are presented in Figure 2.
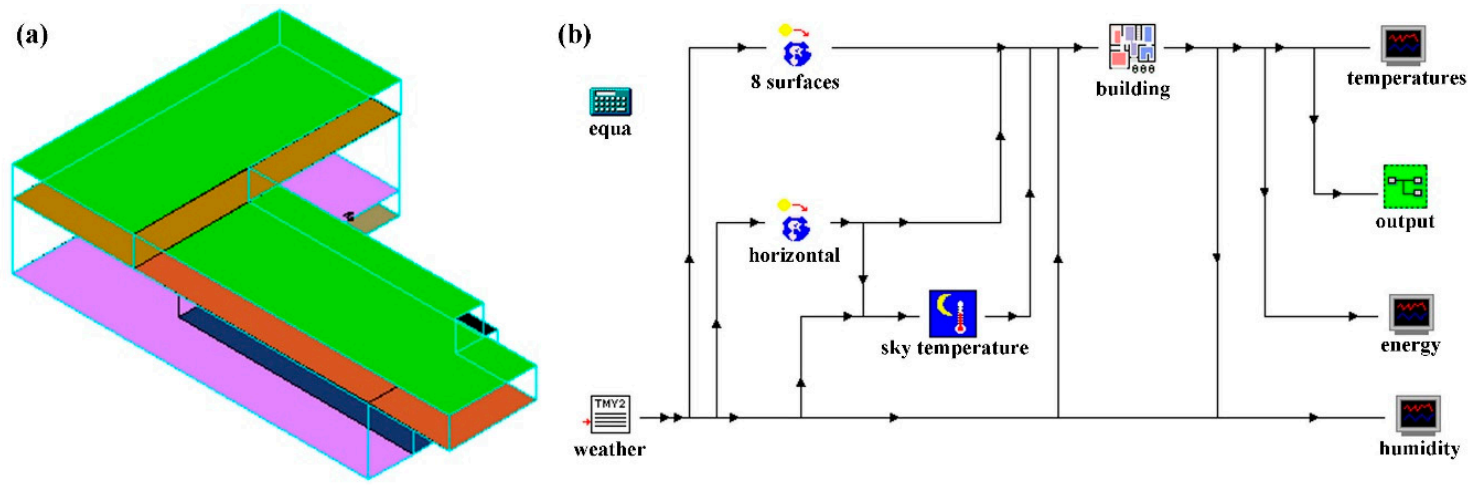

Figure 2. (a) The building's computational simulation model and (b) calculation logical diagram introduced in Transient System Simulation Tool (TRNSYS) for the heating and cooling load calculation.

The fundamental assumptions regarding the heating and cooling load calculation are:

- The ventilation requirements for all the conditioned spaces with human presence (thermal zone 2) was assumed equal to $600 \mathrm{~m}^{3} / \mathrm{h} \mathrm{[31]}$.

- The air penetration in the building's indoor space was calculated according to a relevant approach introduced by ASHRAE [30], according to which the air penetration rate is given by the relationship:

$$
\mathrm{ACH}=\mathrm{K}_{1}+\mathrm{K}_{2} \cdot\left(\mathrm{T}_{\mathrm{zone}}-\mathrm{T}_{\mathrm{amb}}\right)+\mathrm{K}_{3} \cdot \text { windspeed }
$$

where $\mathrm{ACH}$ is the air penetration rate in $\mathrm{m}^{3} / \mathrm{h}$ and $\mathrm{K}_{1}, \mathrm{~K}_{2}, \mathrm{~K}_{3}$ are factors depending on the air sealing of the openings [30]. 
- The daily and weekly operation schedule of the examined building was provided by the management: Twenty people staff, from 7:00-17:00 daily, none during weekends.

- The building is fully detached, without any neighbouring physical (e.g., trees) or technical (e.g., buildings) obstacles. Hence, no shading occurs for the building's openings located in the western, southern and eastern sides of the ground and first floor. For these openings, the shading factors are set equal to zero (null shading).

- The internal heat gains for thermal zone 2 were calculated by accounting the occupancy of the staff, the usage of electronic devices, etc., as defined in the relevant directives [29,30]. Particularly for thermal zone 1, a heat gain of $50 \mathrm{~kW}$-th was introduced. This heat gain is formulated by the operation of the installed in this zone electrical and electronic equipment and is given as a technical specification by the equipment manufacturers. This amount of heat is disposed permanently with the operation of the hydro power plant, and can be considered constant, regardless of the electrical power output fluctuations.

The indoor space thermal comfort conditions and other simulation parameters are presented in Table 1. Particularly regarding the required thermal comfort conditions for the basement room, the dry bulb temperature is set equal to $\mathrm{T}_{\mathrm{cm}}=30{ }^{\circ} \mathrm{C}$ and the relative humidity is set at $45 \%$, according to the suggested operation conditions for the installed equipment and machinery in this specific room, provided by their manufacturers. For thermal zone 2, the thermal comfort conditions are set according to the international standards, namely the required indoor space temperature is set at $\mathrm{T}_{\mathrm{R}}=20^{\circ} \mathrm{C}$ and the relative humidity at $45 \%$.

Table 1. Simulation parameters and thermal comfort conditions for the heating and cooling load calculation.

\begin{tabular}{|c|c|c|c|c|c|c|c|c|}
\hline \multirow{3}{*}{ Thermal Zone } & \multicolumn{4}{|c|}{ Thermal Comfort Conditions } & \multirow{3}{*}{$\begin{array}{c}\text { Air } \\
\text { Penetration }\end{array}$} & \multirow{3}{*}{$\begin{array}{c}\text { Air } \\
\text { Ventilation } \\
\left(\mathrm{m}^{3} / \mathrm{h}\right)\end{array}$} & \multirow{2}{*}{\multicolumn{2}{|c|}{ Internal Gains }} \\
\hline & \multicolumn{2}{|c|}{ Heating } & \multicolumn{2}{|c|}{ Cooling } & & & & \\
\hline & $\begin{array}{c}\text { Temperature } \\
\left({ }^{\circ} \mathrm{C}\right)\end{array}$ & $\begin{array}{c}\text { Relative } \\
\text { Humidity (\%) }\end{array}$ & $\begin{array}{c}\text { Temperature } \\
\left({ }^{\circ} \mathrm{C}\right)\end{array}$ & $\begin{array}{c}\text { Relative } \\
\text { Humidity (\%) }\end{array}$ & & & $\begin{array}{l}\text { Human } \\
\text { Beings (W) }\end{array}$ & $\begin{array}{l}\text { Devices } \\
\text { (W) }\end{array}$ \\
\hline $\begin{array}{c}\text { Offices and } \\
\text { shared spaces } \\
\text { (thermal zone } 2 \text { ) }\end{array}$ & 20 & 45 & 26 & 45 & ASHRAE & 600 & 1600 & 2529 \\
\hline $\begin{array}{l}\text { Basement } \\
\text { equipment room } \\
\text { (thermal zone } 1 \text { ) }\end{array}$ & 30 & 45 & 30 & 45 & ASHRAE & - & 0 & 50,000 \\
\hline
\end{tabular}

For the calculation of the heating and cooling load it is assumed that the thermal conditions as defined in Table 1 are maintained constantly during the operation periods of the building.

The monthly and annual values of the heating and cooling load, separately for the thermal zones 1 and 2 and for the total building are presented in Table 2.

The specific heating and cooling annual load are calculated versus the total covered area of the conditioned space of each thermal zone and the total conditioned space covered area in the building (135 $\mathrm{m}^{2}$ for thermal zone 1, $427 \mathrm{~m}^{2}$ for thermal zone 2 and $562 \mathrm{~m}^{2}$ for the whole building).

In Table 3 the monthly and annual peak heating and cooling power demand is presented for the thermal zones 1 and 2 and for the whole building. 
Table 2. Monthly analysis of the heating and cooling load.

\begin{tabular}{|c|c|c|c|c|c|c|}
\hline \multirow{3}{*}{ Months } & \multicolumn{6}{|c|}{ Monthly Total Thermal Loads (kWh) } \\
\hline & \multicolumn{2}{|c|}{ Thermal Zone 1} & \multicolumn{2}{|c|}{ Thermal Zone 2} & \multicolumn{2}{|c|}{ Total Building } \\
\hline & Heating & Cooling & Heating & Cooling & Heating & Cooling \\
\hline January & 0 & 16,829 & 14,425 & 0 & 14,425 & 16,829 \\
\hline February & 0 & 15,465 & 12,154 & 0 & 12,154 & 15,465 \\
\hline March & 0 & 18,451 & 9044 & 0 & 9044 & 18,451 \\
\hline April & 0 & 18,878 & 5397 & 0 & 5397 & 18,878 \\
\hline May & 0 & 20,659 & 2623 & 0 & 2623 & 20,659 \\
\hline June & 0 & 21,312 & 540 & 33 & 540 & 21,345 \\
\hline July & 0 & 23,390 & 0 & 718 & 0 & 24,108 \\
\hline August & 0 & 23,323 & 0 & 311 & 0 & 23,635 \\
\hline September & 0 & 21,468 & 833 & 0 & 833 & 21,468 \\
\hline October & 0 & 20,441 & 5164 & 0 & 5164 & 20,441 \\
\hline November & 0 & 17,967 & 10,556 & 0 & 10,556 & 17,967 \\
\hline December & 0 & 17,425 & 13,362 & 0 & 13,362 & 17,425 \\
\hline Totals & 0 & 235,607 & 74,095 & 1063 & 74,095 & 236,670 \\
\hline Specific load $\left(\mathrm{kWh} / \mathrm{m}^{2}\right)$ & 0 & $1,745.24$ & 173.53 & 2.49 & 131.84 & 421.12 \\
\hline Total heating and cooling & \multicolumn{2}{|c|}{235,607} & \multicolumn{2}{|c|}{75,158} & \multicolumn{2}{|c|}{310,765} \\
\hline $\begin{array}{l}\text { Total heating and cooling } \\
\text { specific load }\left(\mathrm{kWh} / \mathrm{m}^{2}\right)\end{array}$ & \multicolumn{2}{|c|}{$1,745.24$} & \multicolumn{2}{|c|}{176.01} & \multicolumn{2}{|c|}{552.96} \\
\hline
\end{tabular}

Table 3. Monthly peak heating and cooling power demand.

\begin{tabular}{ccccccc}
\hline \multirow{2}{*}{ Months } & \multicolumn{7}{c}{ Monthly Peak Loads (kW) } \\
\cline { 2 - 7 } & \multicolumn{2}{c}{ Thermal Zone 1 } & Thermal Zone 2 & \multicolumn{2}{c}{ Total Building } \\
\cline { 2 - 7 } & Heating & Cooling & Heating & Cooling & Heating & Cooling \\
\hline January & 0 & 24.63 & 144.15 & 0 & 144.15 & 24.63 \\
February & 0 & 24.81 & 133.27 & 0 & 133.27 & 24.81 \\
March & 0 & 26.35 & 104.57 & 0 & 104.57 & 26.35 \\
April & 0 & 28.06 & 70.3 & 0 & 70.3 & 28.06 \\
May & 0 & 29.43 & 73.01 & 0 & 73.01 & 29.43 \\
June & 0 & 31.37 & 29.09 & 7.29 & 29.09 & 38.56 \\
July & 0 & 32.73 & 0 & 19.16 & 0 & 51.7 \\
August & 0 & 32.69 & 0 & 12.69 & 0 & 45.21 \\
September & 0 & 31.62 & 29.55 & 0 & 29.55 & 31.62 \\
October & 0 & 28.81 & 78.09 & 0 & 78.09 & 28.81 \\
November & 0 & 26.52 & 115.27 & 0 & 115.27 & 26.52 \\
December & 0 & 24.5 & 132.86 & 0 & 132.86 & 24.5 \\
Maximum & 0 & 32.73 & 144.15 & 19.16 & 144.15 & 51.7 \\
\hline
\end{tabular}

In Figure 3, the annual fluctuation of the total heating and cooling load for the whole building is presented.

The dimensioning of the required active systems for the indoor space conditioning will be performed on the basis of the 10th maximum value for heating and cooling, which have been calculated equal to $123.8 \mathrm{~kW}$ and $44.9 \mathrm{~kW}$, respectively [30]. 


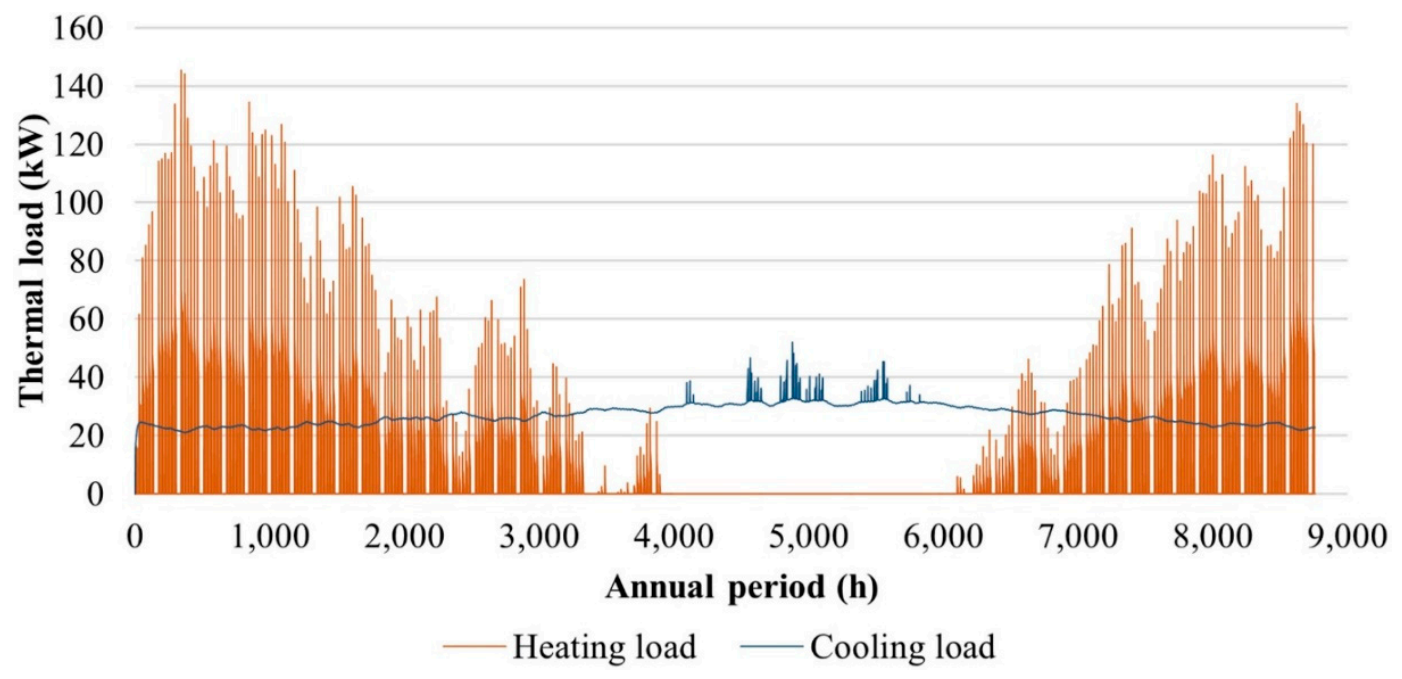

Figure 3. Annual fluctuation of the heating and cooling load of the whole building.

\section{The Investigated Active Cooling Systems}

Two alternative active cooling systems will be investigated in this article:

- Variable air volume-Inverter type (VAV) system, with an air-duct network for the distribution of cooling and heating in the conditioned spaces.

- Variable refrigerant volume, inverter type (VRV) system, with a refrigerant pipeline network for the distribution of cooling and heating in the conditioned spaces.

\subsection{Essential Layout of the Proposed VAV System}

As already underlined in the introductory section, the investigated VAV is introduced aiming to approach maximum energy saving, by utilizing physical cooling and heat recovery processes. This can be easily achieved in the under consideration case study if the following facts are taken into account:

- Considerable cooling load for thermal zone 1 exists during the whole annual period, including winter, during which the ambient temperature is much lower than the required indoor temperature in thermal zone $1\left(30^{\circ} \mathrm{C}\right)$. This means that cooling of thermal zone 1 can be achieved, for most time during the year, simply by pumping cold, outdoor fresh air.

- At the same time, the required temperature in thermal zone 2 (offices and shared spaces at the ground and first floor) during winter is set at $20^{\circ} \mathrm{C}$ (Table 1), namely considerably lower than the required temperature in thermal zone $1\left(30^{\circ} \mathrm{C}\right)$. This means that, alternatively, the cooling of thermal zone 1 can be also achieved during winter by simply pumping indoor air from thermal zone 2 and supplying it in thermal zone 1 . At the same time, warm air from thermal zone 1 can be returned back to thermal zone 2, covering a part of the existing heating load. Hence, with this circulation air flow between thermal zones 1 and 2, at the same time the existing cooling load in thermal zone 1 and the heating load in thermal zone 2 can be covered.

- Additional heating load of thermal zone 2 can be also covered with heat recovery from the cooling load of thermal zone 1 , covered with fresh air flow. 
Detailed description of the operation of this system is provided in Section 4, with the presentation of the proposed operation algorithm. In Figure 4, a simplified layout of the proposed system is presented, in a more conceivable way.

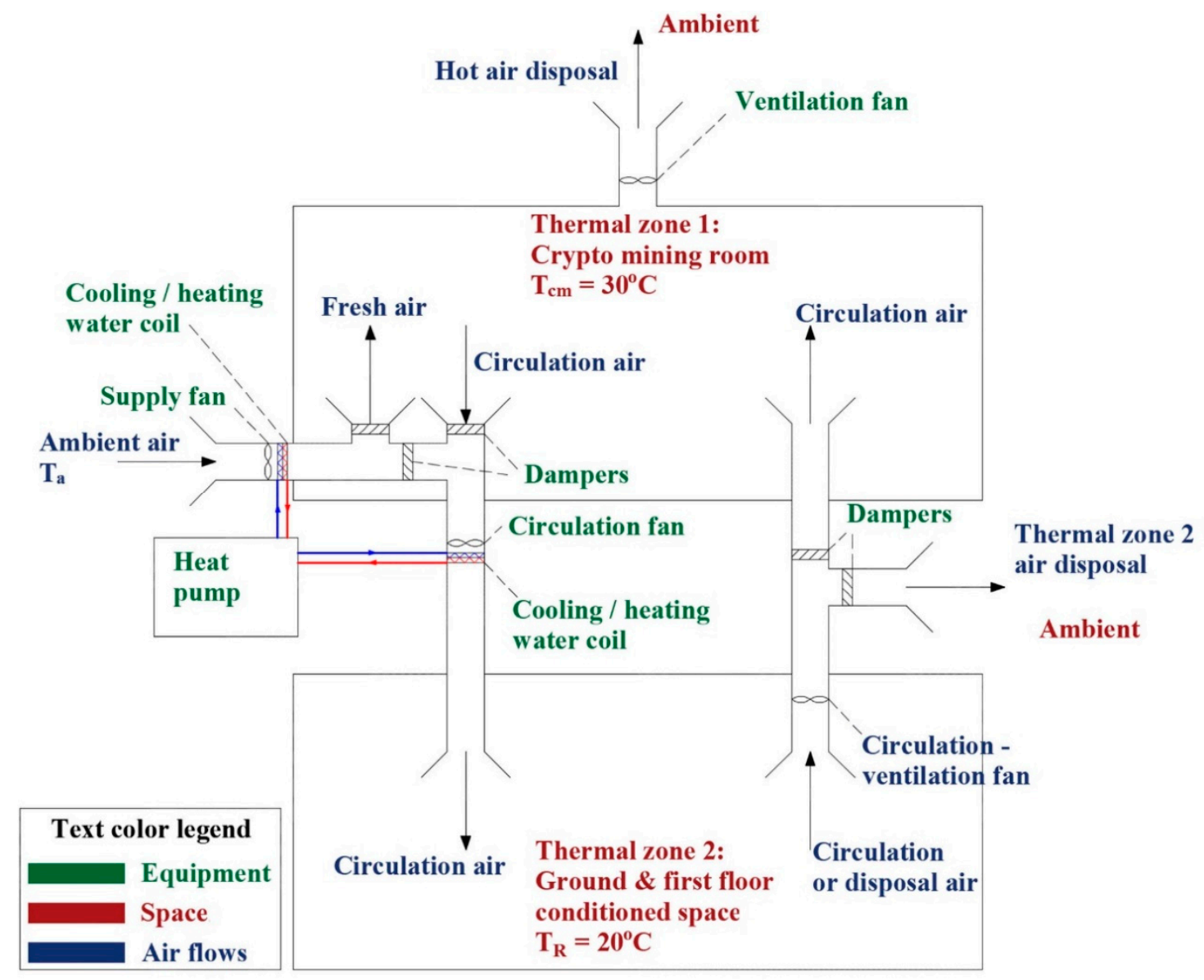

Figure 4. Simplified layout of the proposed VAV system.

As seen in Figure 4, the basic required equipment for the implementation of the proposed system is:

- a heat pump, for the production of cooling and heating whenever the physical air flows are not adequate to undertake the existing load.

- in total four (4) fans, powered by inverter driven motors, with the following tasks:

- $\quad$ one fan for the supply of fresh air in thermal zone 1 and the ventilation of the thermal zone 2 indoor space

- $\quad$ one fan for the disposal of the hot air from thermal zone 1 to the ambient

- $\quad$ one fan for the supply of hot air from thermal zone 1 to thermal zone 2

- $\quad$ one fan for the supply of conditioned air from thermal zone 2 to thermal zone 1 or the disposal of air from thermal zone 2 to the ambient.

- a number of dumpers, which, in combination with the motors' inverters, will regulate the air flow rates and routes through the air-duct network.

- the appropriate air-ducts distribution network for the transportation and distribution of cooling and heating to the conditioned space. 


\subsection{Layout of the VRV System}

The proposed VRV system consists of one outdoor unit and three discrete distribution networks, one for thermal zone 1 and two more for the ground and the first floor (thermal zone 2). The whole network consists of:

- A central outdoor unit (heat pump);

- a number of indoor, wall-mounted and roof-mounted, terminal units; each one of them supplies conditioned air for particular space and is controlled with its own, autonomous remote control;

- the supply and return refrigerant pipelines;

- a number of flow separators and branch selectors located properly in the refrigerant pipelines, depending on the flow route and the network's topology.

The dimensioning of the indoor terminal units is determined by the heating and cooling load of the indoor discrete space that each one of them serves. Respectively, the dimensioning of the outdoor unit arises from the total cooling load of thermal zone 1 . The vertical hydraulic diagram of the whole system is given in Figure 5. As shown in this diagram, the central heat pump is connected with the indoor branch selectors with triple refrigerant pipelines, employed for liquid, gas refrigerant and for heat recovery flow. In this way, the removed heat from the cooling thermal zone 1 will be fully utilized for the coverage of equal heating load of thermal zone 2. 


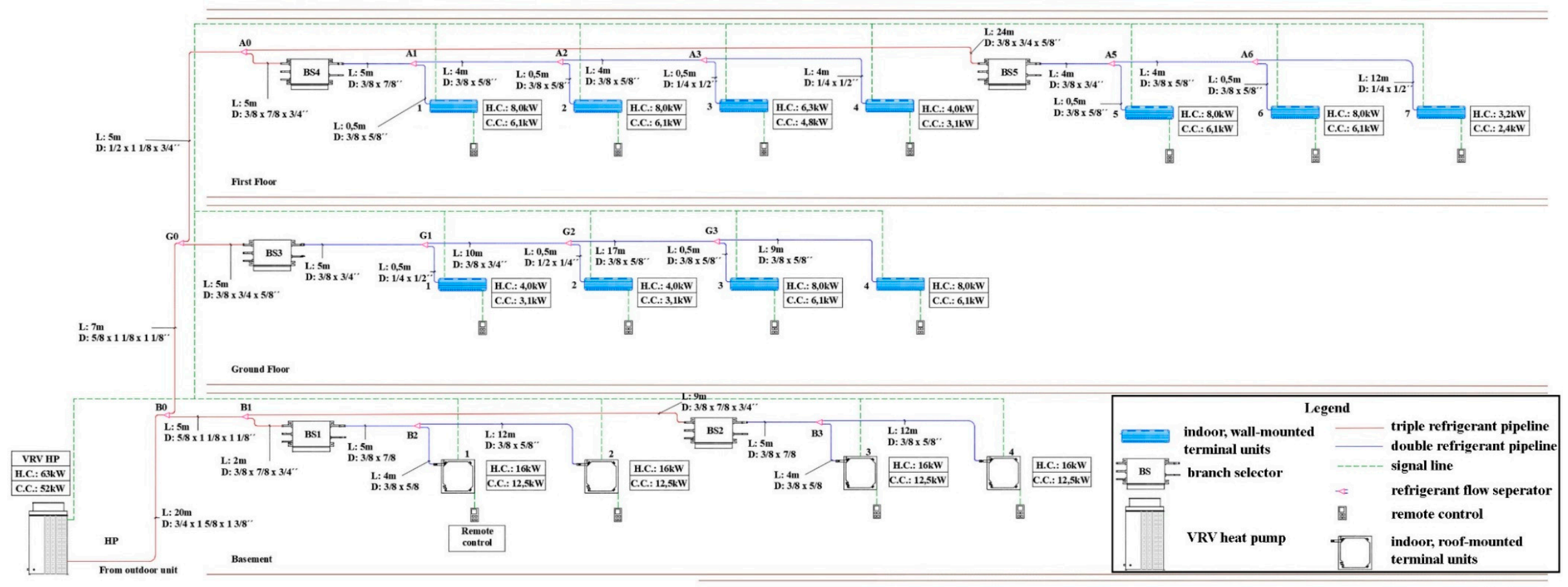

Figure 5. Vertical diagram of the VRV system. 


\section{Computational Simulation of the Investigated Active Cooling Systems}

In this section, the computational simulation of the annual operation of the investigated active cooling systems is analyzed and presented. The final goal is the estimation of the annual electricity consumption for the cooling of thermal zone 1 and the percentage of the heating load of thermal zone 2 (offices and shared spaces) that can be annually covered by the disposed heat recovery from the thermal zone 1 cooling process.

\subsection{Operation Algorithm of the VAV System}

The operation algorithm of the proposed VAV system in rough lines is:

- The cooling load coverage of thermal zone 1 is the fundamental task of the whole system, with highest priority.

- The heating load coverage of thermal zone 2 is accomplished in a second stage, by exploiting the available thermal energy disposed from the cooling process of thermal zone 1.

- For the coverage of the thermal zone 1 cooling load, the following cooling sources are exploited with the particular order of priority:

- $\quad$ fresh air flow required for the ventilation of the thermal zone 2 indoor space

- $\quad$ recirculation air flow from the conditioned space of thermal zone 2, in the case of existing concurrent heating load

- $\quad$ additional fresh air flow from the ambient environment

- $\quad$ operation of the central heat pump unit.

The above roughly described operation algorithm is thoroughly analyzed below. The following process refers to each discrete calculation time step (one hour). In this operation algorithm presentation, the symbols presented in Table 4 are used, all of them referring to the current time calculation step.

1. Case 1: Ambient temperature higher than indoor temperature

If the ambient temperature $T_{a}$ is higher than the required indoor space temperature $T_{c m}$ in thermal zone 1 , a case exclusively expected during summer, then no physical cooling can be achieved. In this case, the total cooling load $Q_{\mathrm{cm}}$ of thermal zone 1 is exclusively covered by the available heat pump:

$$
\mathrm{q}_{\mathrm{hp}}=\mathrm{Q}_{\mathrm{cm}}
$$

where $\mathrm{q}_{\mathrm{hp}}$ is the final cooling power produced by the heat pump.

Obviously, in this case, with the ambient temperature higher than the required indoor space temperature in thermal zone $1\left(30^{\circ} \mathrm{C}\right)$, no heating load for thermal zone 2 is expected, hence, there is no sense to investigate the option of thermal power recovery for the indoor space heating.

2. Case 2: Ambient temperature lower than indoor temperature

If the ambient temperature $T_{a}$ is lower than the required indoor space temperature $T_{c m}$ in thermal zone 1, a case met for most of the time during the annual period, then physical cooling can be implemented, by simply pumping fresh outdoor air into the conditioned space, without any mechanical cooling required from the heat pump. Physical cooling can be alternatively achieved by recirculating air between thermal zone $2\left(\mathrm{~T}_{\mathrm{R}}=20^{\circ} \mathrm{C}\right)$ and thermal zone $1\left(\mathrm{~T}_{\mathrm{cm}}=30^{\circ} \mathrm{C}\right)$. The latter can be combined with the heating load coverage of thermal zone 2 during winter. 
Table 4. Notation for the involved magnitudes in the operation algorithm of the VAV system.

\begin{tabular}{|c|c|}
\hline \multicolumn{2}{|r|}{ Temperatures (in ${ }^{\circ} \mathrm{C}$ ) } \\
\hline Ta: & the ambient temperature \\
\hline Tcm: & the indoor space temperature in thermal zone 1 \\
\hline TR: & the indoor space temperature in thermal zone 2 \\
\hline \multicolumn{2}{|r|}{ Air mass flow rates (in kg/s) } \\
\hline$\dot{\mathrm{m}}_{\mathrm{V}}:$ & fresh air mass flow rate required for the ventilation of the thermal zone 2 indoor space \\
\hline$\dot{\mathrm{m}}_{\mathrm{cm}}:$ & fresh air mass flow rate required for the coverage of the thermal zone 1 cooling load \\
\hline$\dot{\mathrm{m}}_{\mathrm{R}}:$ & recirculation air mass flow rate between thermal zones 1 and 2 \\
\hline$\dot{\mathrm{m}}_{\mathrm{Rmax}}:$ & maximum recirculation air mass flow rate, determined by the installed fan \\
\hline$\dot{\mathrm{m}}_{\mathrm{N}}:$ & additional fresh air mass flow rate for the thermal zone 1 cooling \\
\hline$\dot{\mathrm{m}}_{\mathrm{Nmax}}:$ & maximum fresh air mass flow rate, determined by the installed fan \\
\hline \multicolumn{2}{|r|}{ Heating and cooling power (in kW) } \\
\hline Qcm: & cooling load of thermal zone 1 \\
\hline QR: & heating load of thermal zone 2 \\
\hline QRD: & $\begin{array}{c}\text { heating load remaining for the thermal zone } 2 \text { space, after the heat recovery of the disposed heat from the thermal } \\
\text { zone } 1 \text { physical cooling }\end{array}$ \\
\hline qhp: & cooling power production from the heat pump unit for the thermal zone 1 \\
\hline qv: & cooling power corresponding to the fresh air mass flow rate $\dot{\mathrm{m}}_{\mathrm{v}}$ \\
\hline qvem: & cooling power coverage of the cooling load Qcm from the fresh ventilation air flow \\
\hline qr: & recovered thermal power from the thermal zone 1 cooling to be exploited for the heating of thermal zone 2 \\
\hline qsur: & recovered thermal power surplus \\
\hline qRc: & cooling load coverage of thermal zone 1 from the heating load of thermal zone 2 \\
\hline qRth: & heating load coverage of thermal zone 2 from the cooling load heat recovery \\
\hline qNem: & cooling load of the thermal zone 1 coverage from the increased fresh air mass flow rate \\
\hline qRN: & heating load of the thermal zone 2 covered by the recovered thermal power qr \\
\hline \multicolumn{2}{|r|}{ Specific enthalpies (in kJ/kgK) } \\
\hline ha: & specific enthalpy of the fresh ambient air \\
\hline hcm: & specific enthalpy of the indoor air in thermal zone 1 \\
\hline hR: & specific enthalpy of the indoor air in thermal zone 2 \\
\hline$\Delta$ ha: & specific enthalpies differences: $\mathrm{hcm}$ - ha \\
\hline$\Delta \mathrm{hR}:$ & specific enthalpies differences: $h c m-h R$ \\
\hline
\end{tabular}

In this current case $\left(T_{a}<T_{c m}\right)$, a number of sub-cases must be investigated. The main concept is to exploit the fresh air flow required for the ventilation of the thermal zone 2 indoor space to cool down thermal zone 1 . Hence, fresh air of the low ambient temperate $T_{a}$ is pumped into thermal zone 1 to remove the produced thermal power and keep the indoor space temperature at the required value of $\mathrm{T}_{\mathrm{cm}}=30^{\circ} \mathrm{C}$.

If $\mathrm{q}_{\mathrm{v}}$ is the cooling power that corresponds to this fresh air flow, this power is given by the relationship:

$$
\mathrm{q}_{\mathrm{v}}=\dot{\mathrm{m}}_{\mathrm{v}} \cdot \Delta \mathrm{h}_{\mathrm{a}}=\dot{\mathrm{m}}_{\mathrm{v}} \cdot\left(\mathrm{h}_{\mathrm{cm}}-\mathrm{h}_{\mathrm{a}}\right)
$$

where $\dot{m}_{V}$ is the required air mass flow rate for the ventilation of the thermal zone 2 indoor space and $\Delta h_{a}$ is the specific enthalpies difference between the thermal zone 1 space $h_{c m}$ and the ambient air $h_{a}$. If $Q_{c m}$ is the cooling load of thermal zone 1 at the current calculation time step, two sub-cases are distinguished:

- Case 2.1: $\mathrm{q}_{\mathrm{v}}>\mathrm{Q}_{\mathrm{cm}}$

If the cooling power $\mathrm{q}_{\mathrm{v}}$ of the fresh ventilation air flow is higher than the cooling load $\mathrm{Q}_{\mathrm{cm}}$ of thermal zone 1 , then the cooling load $\mathrm{Q}_{\mathrm{cm}}$ can be totally covered by the fresh air flow. In order not to overcool down the conditioned space, the mass flow rate $\dot{\mathrm{m}}_{\mathrm{cm}}$ required for the cooling process will be:

$$
\dot{\mathrm{m}}_{\mathrm{cm}}=\frac{\mathrm{Q}_{\mathrm{cm}}}{\Delta \mathrm{h}_{\mathrm{a}}}
$$

The cooling power coverage from the fresh air flow $\mathrm{q}_{\mathrm{vcm}}$ will be equal to the total load:

$$
\mathrm{q}_{\mathrm{vcm}}=\mathrm{Q}_{\mathrm{cm}}
$$


Obviously, the required cooling power production $\mathrm{q}_{\mathrm{hp}}$ from the heat pump will be null:

$$
\mathrm{q}_{\mathrm{hp}}=0
$$

In the case of any existing concurrent heating load $Q_{R}$ for thermal zone 2, the disposed heat from the cooling space can be exploited to cover a part or all of it. The thermal power $\mathrm{q}_{\mathrm{r}}$ that can be recovered for the heating of thermal zone 2 is given by the relationship:

$$
\mathrm{q}_{\mathrm{r}}=\dot{\mathrm{m}}_{\mathrm{cm}} \cdot \Delta \mathrm{h}_{\mathrm{R}}=\dot{\mathrm{m}}_{\mathrm{cm}} \cdot\left(\mathrm{h}_{\mathrm{cm}}-\mathrm{h}_{\mathrm{R}}\right)
$$

where $\Delta h_{R}$ is the specific enthalpies difference between thermal zones $1 h_{c m}$ and $2 h_{R}$. Two sub-cases are distinguished:

\section{- Case 2.1.1: $\mathrm{Q}_{\mathrm{R}} \leq \mathrm{q}_{\mathrm{r}}$}

If the heating load $Q_{R}$ of thermal zone 2 is lower than the recovered heat $\mathrm{q}_{\mathrm{r}}$ from the cooling process of thermal zone 1 , then all or a part of the heating load can be covered from the heat recovery $\mathrm{q}_{\mathrm{r}}$, depending on the required mass flow rate $\dot{m}_{R}$, which must be recirculated between these two thermal zones. Specifically, in order to cover all the heating load of thermal zone 2, the required mass flow rate should be:

$$
\mathrm{Q}_{\mathrm{R}}=\dot{\mathrm{m}}_{\mathrm{R}} \cdot \Delta \mathrm{h}_{\mathrm{R}} \Leftrightarrow \dot{\mathrm{m}}_{\mathrm{R}}=\frac{\mathrm{QR}}{\Delta \mathrm{h}_{\mathrm{R}}}
$$

If $\dot{m}_{R \max }$ is the maximum mass flow rate that the fan can provide, then:

- Case 2.1.1.a: $\dot{\mathrm{m}}_{\mathrm{R}} \leq \dot{\mathrm{m}}_{\mathrm{Rmax}}$ :

All the heating load $Q_{R}$ can be covered by the disposed heat from the cooling process:

$$
\mathrm{q}_{\mathrm{R} \text { h }}=\mathrm{Q}_{\mathrm{R}}
$$

The remaining heating demand $\mathrm{Q}_{\mathrm{RD}}$ for thermal zone 2 will be null:

$$
\mathrm{Q}_{\mathrm{RD}}=0
$$

The recovered heat surplus:

$$
\mathrm{q}_{\mathrm{sur}}=\mathrm{q}_{\mathrm{r}}-\mathrm{q}_{\mathrm{R} t h}
$$

from thermal zone 1 is disposed in the ambient.

The mass flow rate from the circulation fan will be $\dot{m}_{R}$.

- Case 2.1.1.b: $\dot{\mathrm{m}}_{\mathrm{R}}>\dot{\mathrm{m}}_{\mathrm{Rmax}}$ :

Only a part of the heating load can be covered by the disposed heat from the cooling process:

$$
\mathrm{q}_{\mathrm{Rth}}=\dot{\mathrm{m}}_{\mathrm{Rmax}} \cdot \Delta \mathrm{h}_{\mathrm{R}}
$$

The remaining heating demand $\mathrm{Q}_{\mathrm{RD}}$ for thermal zone 2 will be:

$$
\mathrm{Q}_{\mathrm{RD}}=\mathrm{Q}_{\mathrm{R}}-\mathrm{q}_{\mathrm{R} \text { th }}
$$

The recovered heat surplus will be null:

$$
\mathrm{q}_{\mathrm{sur}}=0
$$

The mass flow rate from the circulation fan will be $\dot{\mathrm{m}}_{\mathrm{Rmax}}$. 
- Case 2.1.2: $\mathrm{Q}_{\mathrm{R}}>\mathrm{q}_{\mathrm{r}}$

If the heating load $Q_{R}$ of thermal zone 2 is higher than the recovered heat $\mathrm{q}_{\mathrm{r}}$ from the cooling process of thermal zone 1, then all the recovered thermal power can be used for the heating load coverage. The capability of the available fan to provide the required air mass flow rate must be checked again, similarly with the previous sub-section. In order to transfer all the recovered heat to thermal zone 2, the required air mass flow rate must be:

$$
\mathrm{q}_{\mathrm{r}}=\dot{\mathrm{m}}_{\mathrm{R}} \cdot \Delta \mathrm{h}_{\mathrm{R}} \Leftrightarrow \dot{\mathrm{m}}_{\mathrm{R}}=\frac{\mathrm{qr}}{\Delta \mathrm{h}_{\mathrm{R}}}
$$

If $\dot{\mathrm{m}}_{\mathrm{Rmax}}$ is the maximum mass flow rate that the fan can provide, then:

- Case 2.1.2.a: $\dot{\mathrm{m}}_{\mathrm{R}} \leq \dot{\mathrm{m}}_{\mathrm{Rmax}}$ :

All the recovered heat $\mathrm{q}_{\mathrm{R}}$ can be provided for the coverage of the corresponding heating load of thermal zone 2:

$$
\mathrm{q}_{\mathrm{Rth}}=\mathrm{q}_{\mathrm{r}}
$$

The remaining heating demand $\mathrm{Q}_{\mathrm{RD}}$ for thermal zone 2 will be:

$$
\mathrm{Q}_{\mathrm{RD}}=\mathrm{Q}_{\mathrm{R}}-\mathrm{q}_{\mathrm{R} \text { th }}
$$

The recovered heat surplus will be zero:

$$
\mathrm{q}_{\mathrm{sur}}=0
$$

The mass flow rate from the circulation fan will be $\dot{m}_{R}$.

- Case 2.1.2.b: $\dot{\mathrm{m}}_{\mathrm{R}}>\dot{\mathrm{m}}_{\mathrm{Rmax}}$ :

Only a part of the recovered heat can be provided for the thermal zone 2 heating load coverage:

$$
\mathrm{q}_{\mathrm{Rth}}=\dot{\mathrm{m}}_{\mathrm{Rmax}} \cdot \Delta \mathrm{h}_{\mathrm{R}}
$$

The remaining heating demand $\mathrm{Q}_{\mathrm{RD}}$ for thermal zone 2 will be:

$$
Q_{R D}=Q_{R}-q_{R t h}
$$

The recovered heat surplus:

$$
\mathrm{q}_{\mathrm{sur}}=\mathrm{q}_{\mathrm{r}}-\mathrm{q}_{\mathrm{R} \text { h }}
$$

from thermal zone 1 is disposed in the ambient.

The mass flow rate from the circulation fan will be $\dot{m}_{R \max }$.

- Case 2.2: $\mathrm{q}_{\mathrm{v}} \leq \mathrm{Q}_{\mathrm{cm}}$

If the cooling power $\mathrm{q}_{\mathrm{v}}$ of the fresh air mass flow rate $\dot{\mathrm{m}}_{\mathrm{v}}$ is lower than the cooling load $\mathrm{Q}_{\mathrm{cm}}$ of thermal zone 1, then all the available cooling power of the fresh air flow is utilized to cover only a part of the cooling load. The cooling power coverage from the fresh air flow $\mathrm{q}_{\mathrm{vcm}}$ will be equal to the total available cooling power of the flow:

$$
\mathrm{q}_{\mathrm{vcm}}=\mathrm{q}_{\mathrm{v}}=\dot{\mathrm{m}}_{\mathrm{v}} \cdot \Delta \mathrm{h}_{\mathrm{a}}=\dot{\mathrm{m}}_{\mathrm{v}} \cdot\left(\mathrm{h}_{\mathrm{cm}}-\mathrm{h}_{\mathrm{a}}\right)
$$

The thermal power $\mathrm{q}_{\mathrm{r}}$ that can be recovered for the thermal zone 2 heating is given by the relationship:

$$
\mathrm{q}_{\mathrm{r}}=\dot{\mathrm{m}}_{\mathrm{v}} \cdot \Delta \mathrm{h}_{\mathrm{R}}=\dot{\mathrm{m}}_{\mathrm{v}} \cdot\left(\mathrm{h}_{\mathrm{cm}}-\mathrm{h}_{\mathrm{R}}\right)
$$


The remaining cooling load of thermal zone 1 is:

$$
\mathrm{Q}_{\mathrm{cm}}-\mathrm{q}_{\mathrm{v}}
$$

This remaining cooling load is preferable to be covered by disposing the removed thermal power to cover the heating load $Q_{R}$ of the thermal zone 2 space, if there is any. To this end, an air mass flow rate $\dot{m}_{R}$ should be recirculated between the thermal zone $1\left(\mathrm{~T}_{\mathrm{cm}}=30^{\circ} \mathrm{C}\right)$ to the thermal zone 2 spaces $\left(\mathrm{T}_{\mathrm{R}}=20^{\circ} \mathrm{C}\right)$, calculated as presented below:

$$
\mathrm{Q}_{\mathrm{cm}}-\mathrm{q}_{\mathrm{v}}=\dot{\mathrm{m}}_{\mathrm{R}} \cdot \Delta \mathrm{h}_{\mathrm{R}} \Leftrightarrow \dot{\mathrm{m}}_{\mathrm{R}}=\frac{\mathrm{Qcm}-\mathrm{qv}}{\Delta \mathrm{h}_{\mathrm{R}}}
$$

where, as previously, $\Delta \mathrm{h}_{\mathrm{R}}$ is the specific enthalpies differences between the thermal zones 1 and 2. If $\dot{m}_{R \max }$ is the maximum mass flow rate that the fan can provide, then the following sub-cases are distinguished:

- Case 2.2.1: $\dot{\mathrm{m}}_{\mathrm{R}} \leq \dot{\mathrm{m}}_{\mathrm{Rmax}}$ :

In this case the available fan is capable to provide the required air mass flow rate for the removal of the remaining cooling load from thermal zone 1. Yet, it must be further investigated if there is the requirement for the coverage of the corresponding heating load. For this reason two more sub-cases are examined:

- Case 2.2.1.a: $Q_{R} \geq Q_{c m}-q_{v}$ :

In this case, the heating load of thermal zone 2 is higher than the remaining cooling load of thermal zone 1 . Hence, all the remaining cooling load in thermal zone 1 can be covered from the heating of thermal zone 2 . This means that an air mass flow rate $\dot{\mathrm{m}}_{\mathrm{R}}$ will be recirculated from thermal zone 2 (at temperature $T_{R}=20^{\circ} \mathrm{C}$ ) to thermal zone 1 , cooling the latter and, while returning back at the temperature of $30^{\circ} \mathrm{C}$, heating thermal zone 2 . The cooling load coverage $\mathrm{q}_{\mathrm{Rc}}$ from the heating load of thermal zone 2 will be:

$$
\mathrm{q}_{\mathrm{Rc}}=\mathrm{Q}_{\mathrm{cm}}-\mathrm{q}_{\mathrm{v}}
$$

Obviously, the required cooling power production $\mathrm{q}_{\mathrm{hp}}$ from the heat pump will be null:

$$
\mathrm{q}_{\mathrm{hp}}=0
$$

For the heating load coverage calculation of thermal zone 2 , there is a remaining load to be covered equal to:

$$
\mathrm{Q}_{\mathrm{R}}-\mathrm{q}_{\mathrm{Rc}}
$$

This remaining heating load is compared with the recovered thermal power $\mathrm{q}_{\mathrm{r}}$ from the fresh air flow:

A. If $\mathrm{q}_{\mathrm{r}} \geq \mathrm{Q}_{\mathrm{R}}-\mathrm{q}_{\mathrm{Rc}}$ :

Then all the remaining heating load can be potentially covered by the recovered heat with the fresh air flow. To this end, an additional air mass flow rate will be needed, equal to:

$$
\mathrm{Q}_{\mathrm{R}}-\mathrm{q}_{\mathrm{Rc}}=\dot{\mathrm{m}}_{\mathrm{RN}} \cdot \Delta \mathrm{h}_{\mathrm{R}} \Leftrightarrow \dot{\mathrm{m}}_{\mathrm{RN}}=\frac{\mathrm{Q}_{\mathrm{R}}-\mathrm{qRc}}{\Delta \mathrm{h}_{\mathrm{R}}}
$$

The ability of the available fan to transfer this additional air mass flow rate is checked:

A.1. If $\dot{\mathrm{m}}_{\mathrm{R}}+\dot{\mathrm{m}}_{\mathrm{RN}} \leq \dot{\mathrm{m}}_{\mathrm{Rmax}}$ : 
Then the fan is able to transfer the additionally required air mass flow rate, so all the heating load in thermal zone 2 will be covered by the disposed heat from thermal zone 1 cooling with fresh air. The remaining heating load will be null:

$$
\begin{gathered}
q_{R N}=Q_{R}-q_{R c} \\
Q_{R D}=0
\end{gathered}
$$

The total mass flow rate from the fresh air fan will be: $\dot{m}_{R}+\dot{m}_{R N}$

A.2. If $\dot{\mathrm{m}}_{\mathrm{R}}+\dot{\mathrm{m}}_{\mathrm{RN}}>\dot{\mathrm{m}}_{\mathrm{Rmax}}$ :

Then the fan is not able to transfer the entire additionally required air mass flow rate, so only a part of the heating load in thermal zone 2 will be covered by the disposed heat from thermal zone 1 cooling with fresh air:

$$
\mathrm{q}_{\mathrm{RN}}=\left(\dot{\mathrm{m}}_{\mathrm{Rmax}}-\dot{\mathrm{m}}_{\mathrm{R}}\right) \cdot \Delta \mathrm{h}_{\mathrm{R}}
$$

The remaining heating load will be:

$$
\mathrm{Q}_{\mathrm{RD}}=\mathrm{Q}_{\mathrm{R}}-\mathrm{q}_{\mathrm{Rc}}-\mathrm{q}_{\mathrm{RN}}
$$

The total mass flow rate from the fresh air fan will be: $\dot{\mathrm{m}}_{\mathrm{Rmax}}$

B. If $\mathrm{q}_{\mathrm{r}}<\mathrm{Q}_{\mathrm{R}}-\mathrm{q}_{\mathrm{R}}$ :

Then the coverage of the heating load can be potentially equal to the recovered heat, while there will be a remaining heating load $\mathrm{Q}_{\mathrm{RD}}$ to be covered. Again, the capability of the fan to provide the additional required air mass flow rate must be checked. The required air mass flow rate to exploit all the recovered heat $\mathrm{q}_{\mathrm{r}}$ for the thermal zone 2 heating is:

$$
\mathrm{q}_{\mathrm{r}}=\dot{\mathrm{m}}_{\mathrm{RN}} \cdot \Delta \mathrm{h}_{\mathrm{R}} \Leftrightarrow \dot{\mathrm{m}}_{\mathrm{RN}}=\frac{\mathrm{qr}}{\Delta \mathrm{h}_{\mathrm{R}}}
$$

B.1. If $\dot{\mathrm{m}}_{\mathrm{R}}+\dot{\mathrm{m}}_{\mathrm{RN}} \leq \dot{\mathrm{m}}_{\mathrm{Rmax}}$ :

Then the fan is able to transfer the additionally required air mass flow rate, so all the recovered heat $\mathrm{q}_{\mathrm{r}}$ can be exploited for the thermal zone 2 heating.

$$
\mathrm{q}_{\mathrm{RN}}=\mathrm{q}_{\mathrm{r}}
$$

The remaining heating load will be null:

$$
Q_{R D}=Q_{R}-q_{R c}-q_{R N}
$$

The total mass flow rate from the fresh air fan will be: $\dot{\mathrm{m}}_{\mathrm{R}}+\dot{\mathrm{m}}_{\mathrm{RN}}$

B.2. If $\dot{\mathrm{m}}_{\mathrm{R}}+\dot{\mathrm{m}}_{\mathrm{RN}}>\dot{\mathrm{m}}_{\mathrm{Rmax}}$ :

Then the fan is not able to transfer the additionally required air mass flow rate to exploit all the recovered heat. Only a part of the recovered heat can be transferred to thermal zone 2:

$$
\mathrm{q}_{\mathrm{RN}}=\left(\dot{\mathrm{m}}_{\mathrm{Rmax}}-\dot{\mathrm{m}}_{\mathrm{R}}\right) \cdot \Delta \mathrm{h}_{\mathrm{R}}
$$

The remaining heating load will be:

$$
Q_{R D}=Q_{R}-q_{R}-q_{R N}
$$

The total mass flow rate from the fresh air fan will be: $\dot{\mathrm{m}}_{\mathrm{Rmax}}$ 
- Case 2.2.1.b: $Q_{R}<Q_{c m}-q_{v}$ :

In this case, the heating load of thermal zone 2 is lower than the remaining cooling load of thermal zone 1. Only a part of the remaining cooling load in thermal zone 1 can be covered from the heating process of thermal zone 2 , which will be equal to:

$$
\mathrm{q}_{\mathrm{Rc}}=\mathrm{Q}_{\mathrm{R}}
$$

The remaining cooling load:

$$
Q_{c m}-q_{v}-q_{R c}
$$

can be potentially covered by increasing the mass flow rate of the fresh air flow, more than the required value for the indoor space ventilation. To this end, an additional fresh air mass flow rate $\dot{m}_{\mathrm{N}}$ will be required, equal to:

$$
\mathrm{Q}_{\mathrm{cm}}-\mathrm{q}_{\mathrm{v}}-\mathrm{q}_{\mathrm{R}}=\dot{\mathrm{m}}_{\mathrm{N}} \cdot \Delta \mathrm{h}_{\mathrm{a}} \Leftrightarrow \dot{\mathrm{m}}_{\mathrm{N}}=\frac{\mathrm{Q}_{\mathrm{cm}}-\mathrm{q}_{\mathrm{v}}-\mathrm{q}_{\mathrm{Rc}}}{\Delta \mathrm{h}_{\mathrm{a}}}
$$

A total mass flow rate of fresh air is now required, equal to $\dot{m}_{\mathrm{V}}+\dot{\mathrm{m}}_{\mathrm{N}}$.

If $\dot{m}_{\mathrm{Nmax}}$ is the maximum fan's mass flow rate from the ambient environment, then:

If $\dot{\mathrm{m}}_{\mathrm{v}}+\dot{\mathrm{m}}_{\mathrm{N}} \leq \dot{\mathrm{m}}_{\mathrm{Nmax}}$

Then the remaining cooling load is fully covered with the increase of the fresh air flow:

$$
\mathrm{q}_{\mathrm{Ncm}}=\mathrm{Q}_{\mathrm{cm}}-\mathrm{q}_{\mathrm{v}}-\mathrm{q}_{\mathrm{Rc}}
$$

The cooling power production from the heat pump is null:

$$
\mathrm{q}_{\mathrm{hp}}=0
$$

If $\dot{\mathrm{m}}_{\mathrm{V}}+\dot{\mathrm{m}}_{\mathrm{N}}>\dot{\mathrm{m}}_{\mathrm{Nmax}}$

Then the maximum additional mass flow rate from the ambient environment can be:

$$
\dot{\mathrm{m}}_{\mathrm{N}}=\dot{\mathrm{m}}_{\mathrm{Nmax}}-\dot{\mathrm{m}}_{\mathrm{v}}
$$

and the additional cooling load coverage of thermal zone 1 will be:

$$
\mathrm{q}_{\mathrm{Ncm}}=\left(\dot{\mathrm{m}}_{\mathrm{Nmax}}-\dot{\mathrm{m}}_{\mathrm{v}}\right) \cdot \Delta \mathrm{h}_{\mathrm{a}}
$$

The cooling power production from the heat pump will be:

$$
\mathrm{q}_{\mathrm{hp}}=\mathrm{Q}_{\mathrm{cm}}-\mathrm{q}_{\mathrm{v}}-\mathrm{q}_{\mathrm{R}}-\mathrm{q}_{\mathrm{Ncm}}
$$

Obviously, in this sub-case $\left(Q_{R}<Q_{c m}-q_{v}\right)$, the heating load of thermal zone 2 is fully covered by the recovered heat for the cooling of thermal zone 1 . There is no remaining heating load:

$$
\mathrm{Q}_{\mathrm{RD}}=0
$$

\section{- Case 2.2.2: $\dot{\mathrm{m}}_{\mathrm{R}}>\dot{\mathrm{m}}_{\mathrm{Rmax}}$ :}

In this case the available fan is not capable of providing the required air mass flow rate for the removal of the remaining cooling load from thermal zone 1 . The maximum cooling load $\mathrm{q}_{\mathrm{Rmax}}$ that can be removed from the cooling space and be exploited for the concurrent heating of thermal zone 2 is:

$$
\mathrm{q}_{\mathrm{Rmax}}=\dot{\mathrm{m}}_{\mathrm{Rmax}} \cdot \Delta \mathrm{h}_{\mathrm{R}}
$$


As in the previous sub-case, the requirement for the heating load coverage for thermal zone 2 should be checked. Two further sub-cases are distinguished:

- Case 2.2.2.a: $\mathrm{Q}_{\mathrm{R}} \geq \mathrm{q}_{\mathrm{Rmax}}$ :

In this case, the heating load of thermal zone 2 is higher than the maximum load which can be covered by the recovered heat. This means that the cooling load coverage $\mathrm{q}_{\mathrm{Rc}}$ from the heating load of thermal zone 2 will be:

$$
\mathrm{q}_{\mathrm{Rc}}=\dot{\mathrm{m}}_{\mathrm{Rmax}} \cdot \Delta \mathrm{h}_{\mathrm{R}}
$$

Since the maximum air mass flow rate has been reached, the coverage of the thermal zone 2 heating load will be equal to $\mathrm{q}_{\mathrm{Rc}}$. The remaining heating load will be:

$$
\mathrm{Q}_{\mathrm{RD}}=\mathrm{Q}_{\mathrm{R}}-\mathrm{q}_{\mathrm{Rc}}
$$

- Case 2.2.2.b: $\mathrm{Q}_{\mathrm{R}}<\mathrm{q}_{\mathrm{Rmax}}$ :

In this case the heating load of thermal zone 2 is lower than the maximum load which can be covered by the recovered heat. Only a part of the remaining cooling load in thermal zone 1 can be covered by the heating of thermal zone 2 , which will be equal to:

$$
\mathrm{q}_{\mathrm{Rc}}=\mathrm{Q}_{\mathrm{R}}
$$

The required mass flow rate will be:

$$
\dot{\mathrm{m}}_{\mathrm{R}}=\frac{\mathrm{qRc}}{\Delta \mathrm{h}_{\mathrm{R}}}
$$

All the heating load of thermal zone 2 will be covered:

$$
\mathrm{Q}_{\mathrm{RD}}=0
$$

The remaining cooling load of thermal zone 1 for both the above sub-cases will be:

$$
\mathrm{Q}_{\mathrm{cm}}-\mathrm{q}_{\mathrm{v}}-\mathrm{q}_{\mathrm{Rc}}
$$

As in the previous case, this remaining cooling load can be potentially covered by increasing the mass flow rate of the fresh air flow, more than the required value for the indoor space ventilation. To this end, an additional fresh air mass flow rate $\dot{m}_{\mathrm{N}}$ will be required, equal to:

$$
\mathrm{Q}_{\mathrm{cm}}-\mathrm{q}_{\mathrm{v}}-\mathrm{q}_{\mathrm{Rc}}=\dot{\mathrm{m}}_{\mathrm{N}} \cdot \Delta \mathrm{h}_{\mathrm{a}} \Leftrightarrow \dot{\mathrm{m}}_{\mathrm{N}}=\frac{\mathrm{Q}_{\mathrm{cm}}-\mathrm{q}_{\mathrm{v}}-\mathrm{q}_{\mathrm{Rc}}}{\Delta \mathrm{h}_{\mathrm{a}}}
$$

A total mass flow rate of fresh air is now required, equal to $\dot{m}_{\mathrm{V}}+\dot{\mathrm{m}}_{\mathrm{N}}$.

If $\dot{\mathrm{m}}_{\mathrm{Nmax}}$ is the maximum fan's mass flow rate from the ambient environment, then:

If $\dot{\mathrm{m}}_{\mathrm{v}}+\dot{\mathrm{m}}_{\mathrm{N}} \leq \dot{\mathrm{m}}_{\mathrm{Nmax}}$

Then the remaining cooling load is fully covered with the increase of the fresh air flow:

$$
\mathrm{q}_{\mathrm{Ncm}}=\mathrm{Q}_{\mathrm{cm}}-\mathrm{q}_{\mathrm{v}}-\mathrm{q}_{\mathrm{Rc}}
$$

The cooling power production from the heat pump is null:

$$
\mathrm{q}_{\mathrm{hp}}=0
$$

If $\dot{\mathrm{m}}_{\mathrm{v}}+\dot{\mathrm{m}}_{\mathrm{N}}>\dot{\mathrm{m}}_{\mathrm{Nmax}}$ 
Then the maximum additional mass flow rate from the ambient environment can be:

$$
\dot{\mathrm{m}}_{\mathrm{N}}=\dot{\mathrm{m}}_{\mathrm{Nmax}}-\dot{\mathrm{m}}_{\mathrm{v}}
$$

and the additional cooling load coverage of thermal zone 1 will be:

$$
\mathrm{q}_{\mathrm{N}}=\left(\dot{\mathrm{m}}_{\mathrm{Nmax}}-\dot{\mathrm{m}}_{\mathrm{v}}\right) \cdot \Delta \mathrm{h}_{\mathrm{a}}
$$

The cooling power production from the heat pump will be:

$$
\mathrm{q}_{\mathrm{hp}}=\mathrm{Q}_{\mathrm{cm}}-\mathrm{q}_{\mathrm{v}}-\mathrm{q}_{\mathrm{Rc}}-\mathrm{q}_{\mathrm{N}}
$$

The above operation algorithm is graphically depicted in Figure 6.

It must be underlined that with the structure of the proposed operation algorithm, it is intended to maximize the coverage of both the cooling load of thermal zone 1 and the heating load of thermal zone 2 with physical cooling and heat recovery, respectively. Specifically, as it is revealed with the presentation of the operation algorithm, first of all, the cooling load coverage of thermal zone 1 is examined through the fresh air flow for the ventilation requirements of thermal zone 2 . The ventilation of the indoor space is obligatory, according to the relevant directives, hence, given the fact that this fresh air flow exists permanently, the first task is to exploit the corresponding cooling power from this flow, of course if $\mathrm{T}_{\mathrm{a}}<\mathrm{T}_{\mathrm{cm}}$.

Secondly, in case the cooling load is not fully covered in the first step, instead of increasing the fresh air flow, the exploitation of any existing heating load in thermal zone 2 for the coverage of the remaining cooling load is examined. The indoor space temperature in thermal zone 2 is set at $20^{\circ} \mathrm{C}$, while the required temperature in thermal zone 1 is $30^{\circ} \mathrm{C}$. Hence, by circulating air between thermal zones 1 and 2, the first is cooled down and the second is heated. This is the task with the second in order priority towards the full coverage of the cooling load in thermal zone 1.

Thirdly, additional fresh air flow is provided, up to the available fan's maximum flow rate and beyond the ventilation requirements for thermal zone 2, for the coverage of any remaining cooling load in thermal zone 1. Finally, in the case of the cooling load still remaining uncovered in thermal zone 1, the heat pump is put on duty, as the ultimate alternative for cooling power production.

The above essential targets are fulfilled with the proposed operation algorithm. It is certain that with this approach, the contribution of physical cooling and heat recovery, namely without the intervention of the heat pump, is maximized, while the utilization of the latter is limited. The above are clearly depicted in the results from the execution of the computational simulation procedure. 


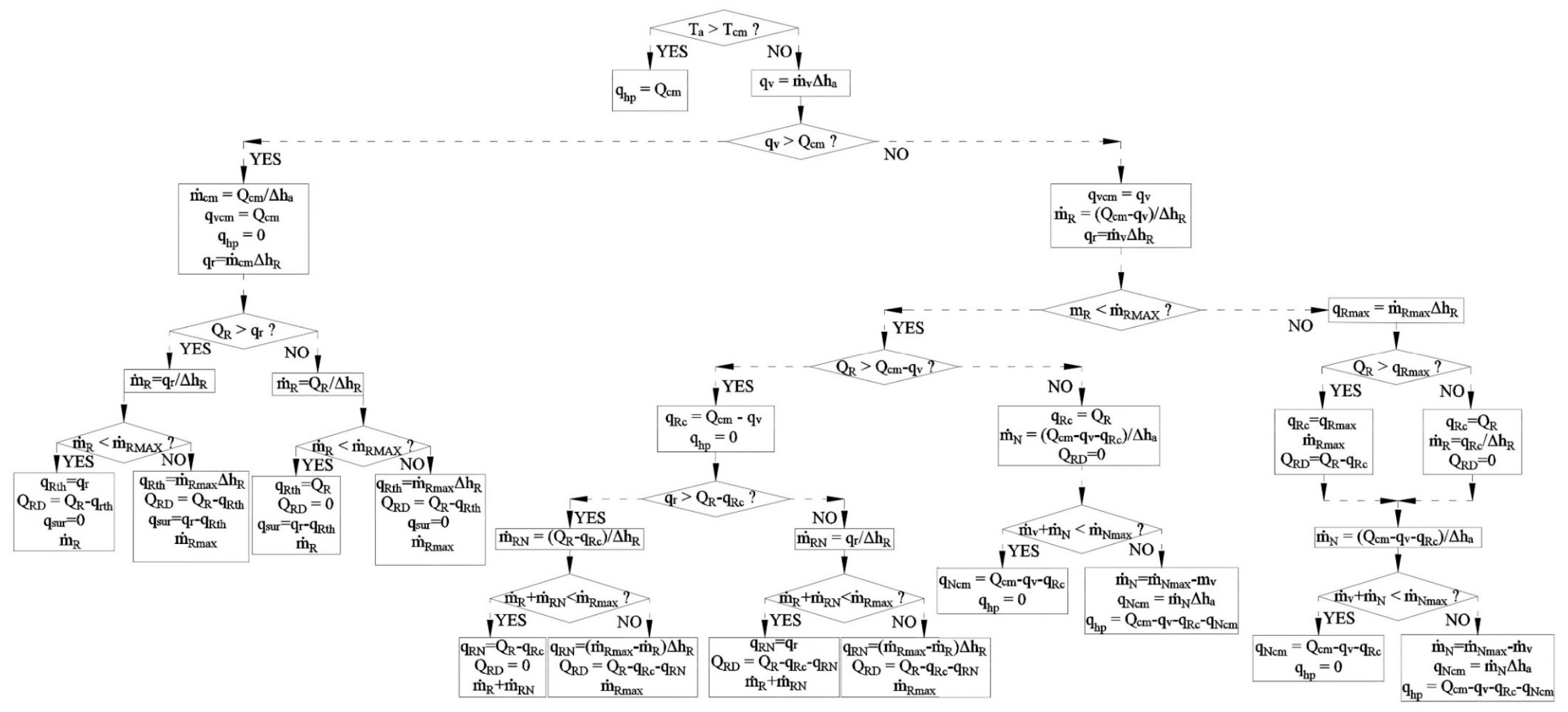

Figure 6. The operation algorithm of the proposed VAV system. 


\subsection{Operation Algorithm of the VRV System}

The operation of the VRV system is simple and conventional. No sophisticated and complex algorithms are introduced. The main advantage of the VRV system is the automatic heat recovery from the thermal zone 1 cooling and its exploitation during winter for the heating of thermal zone 2 . This is provided by the technical specifications of the heat pump itself, by disposing the removed heat from the conditioned thermal zone 1 in the refrigerant pipeline network of thermal zone 2 and supplying this heat to the heated indoor space.

In short lines, the operation algorithm of the VRV system follows the basic lines below:

- the VRV heat pump operates following the cooling load of thermal zone 1 during the whole year

- additionally, the heat pump also operates following the cooling load of thermal zone 2 during the summer

- during winter, the coverage of the thermal zone 1 cooling load enables the corresponding coverage of equal heating load of thermal zone 2

- the continuous operation of the heat pump for the cooling production, even during winter, restricts the flexibility of the unit for simultaneous heating production, hence no heating load can be provided for thermal zone 2 further than the heat recovery during the thermal zone 1 cooling process.

The above fundamental operation principles impose that the cooling load for the whole building is totally covered by the heat pump during the whole year, hence the cooling production practically coincides with the total cooling load annual fluctuation (Figure 3). Additionally, the annual fluctuation of the thermal zone 2 heating load coverage follows the cooling load coverage of thermal zone 1.

Practically, if $Q_{h}$ is the current heating load of thermal zone 2 and $Q_{c m}$ the current cooling load of thermal zone 1 , then the calculation of the heating load coverage $\mathrm{Q}_{\mathrm{hc}}$ from the heat recovery from the cooling load coverage, follows the following simple control:

i. If $\mathrm{Q}_{\mathrm{h}}=0$ or $\mathrm{Q}_{\mathrm{cm}}=0$, then $\mathrm{Q}_{\mathrm{hc}}=0$.

ii. If $Q_{\mathrm{h}}>0$ and $\mathrm{Q}_{\mathrm{cm}}>0$, then:

$$
\begin{aligned}
& \text { a. if } Q_{h} \geq Q_{c m} \text {, then } Q_{h c}=Q_{c m} \\
& \text { b. if } Q_{h}<Q_{c m} \text {, then } Q_{h c}=Q_{h} .
\end{aligned}
$$

\subsection{Calculation Data}

For the realization of the above analyzed operation algorithms, the involved data are the ambient and the indoor space temperatures, the specific enthalpies of the various air conditions and the air mass or volume flow rates.

The ambient temperature $T_{a}$ is presented in Figure $1 b$. The indoor space temperatures $T_{c m}$ and $T_{R}$ are presented in Figure 7, arisen from the heating and cooling load calculation of the building. 


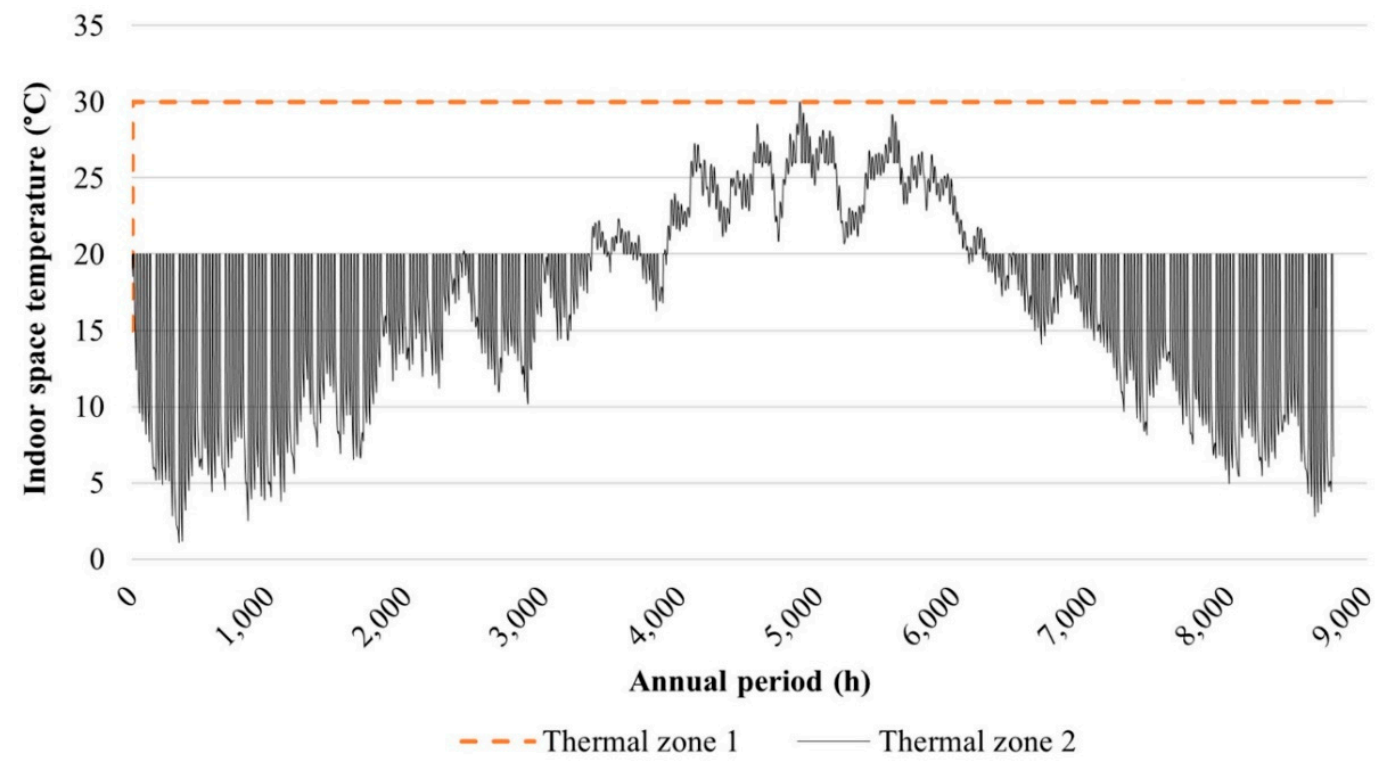

Figure 7. Annual fluctuation of the achieved indoor space temperature in thermal zones 1 and 2.

The specific enthalpies $h_{a}, h_{c m}$ and $h_{R}$ of the ambient air and the indoor air in thermal zones 1 and 2 , respectively are retrieved from the psychrometric chart of air under atmospheric pressure in tabular format [32], given the corresponding annual time series of the temperature and the relative humidity for each one of the three different air conditions. The ambient relative humidity annual time series has been also presented in Figure 1c, with the introduced meteorological data. The relative humidity annual time series for the indoor air in thermal zones 1 and 2 are presented in Figure 8, as calculated with the building's heating and cooling load calculation process.

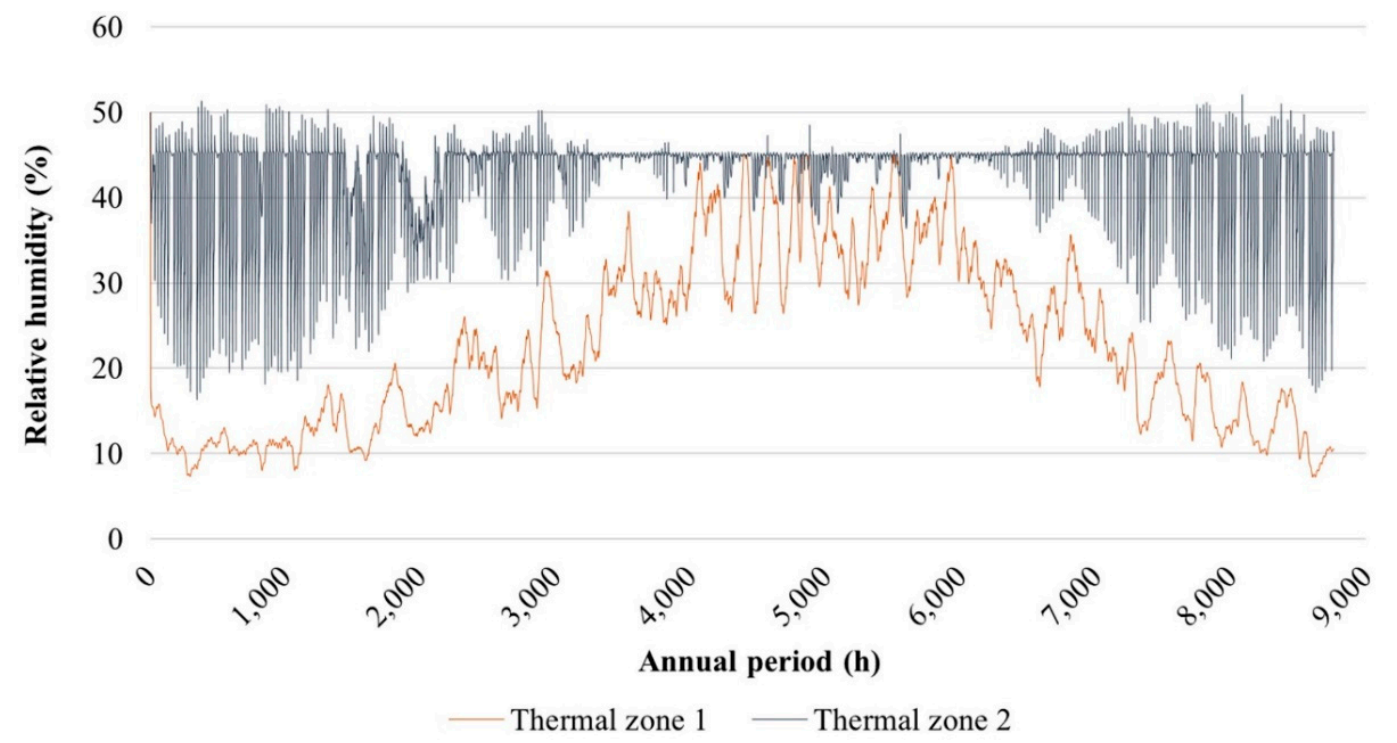

Figure 8. Annual fluctuation of the achieved relative humidity in thermal zones 1 and 2.

The annual fluctuations of the calculated specific enthalpies, following the above mentioned, are presented in Figure 9. Obviously, the indoor air in thermal zone 1 exhibits the highest specific enthalpy for most of the time during the year, due to the almost constantly higher dry bulb temperature. 


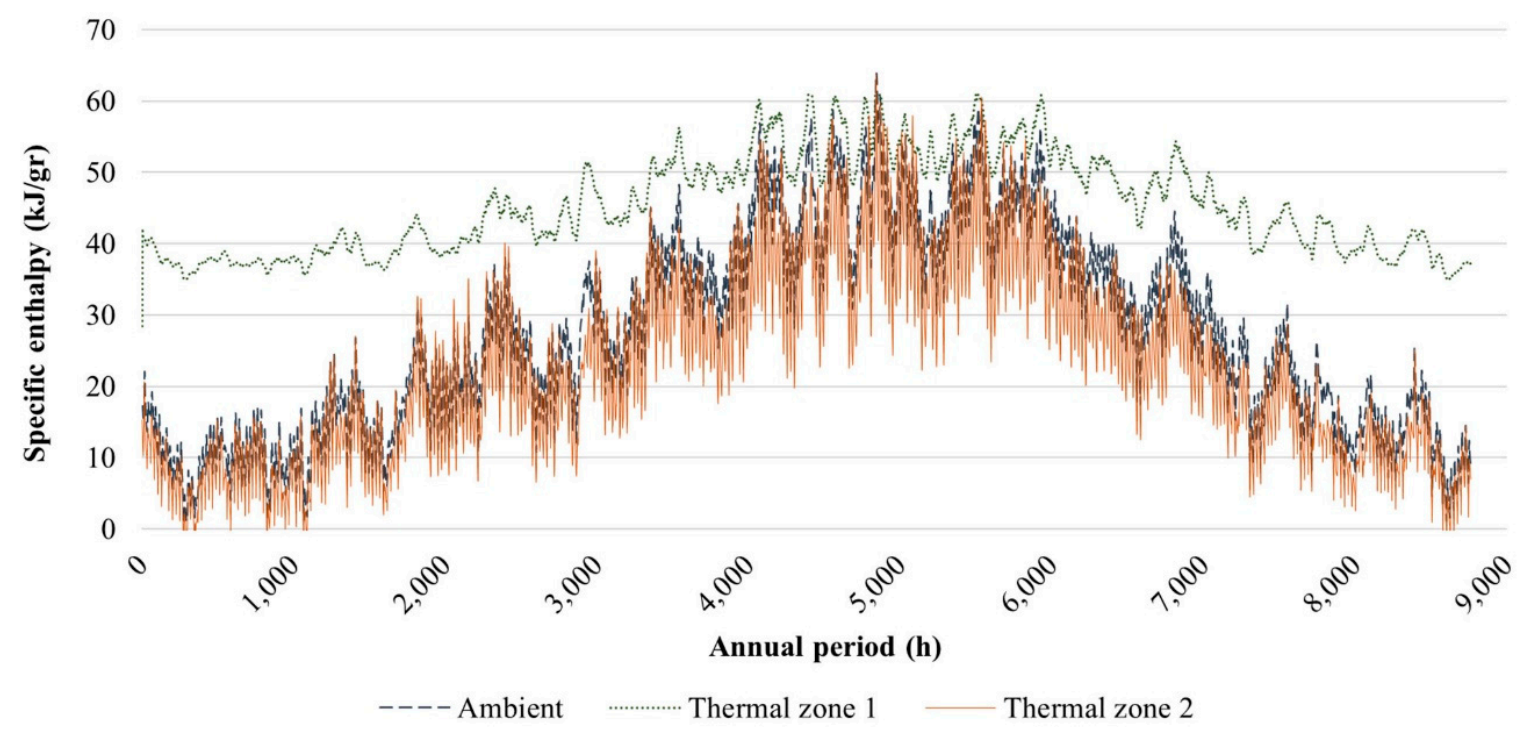

Figure 9. Annual fluctuation of the specific enthalpies in the three different involved atmospheric air states.

Finally, with regard to the involved air mass flow rates, the following data have been introduced:

- Air volume flow rate for the indoor space ventilation in thermal zone $2: \dot{\mathrm{V}}=600 \mathrm{~m}^{3} / \mathrm{h}$, as presented in Table 2.

- Maximum air volume flow rates for the circulation and fresh air fan equal to $6000 \mathrm{~m}^{3} / \mathrm{h}$, defined by the specifications of the selected equipment.

For the conversion of the above presented air volume flow rates to the air mass flow rates required for the execution of the simulation process, the air density fluctuation graph versus the air temperature under the atmospheric pressure $1 \mathrm{~atm}$, presented in Figure 10, was adopted.

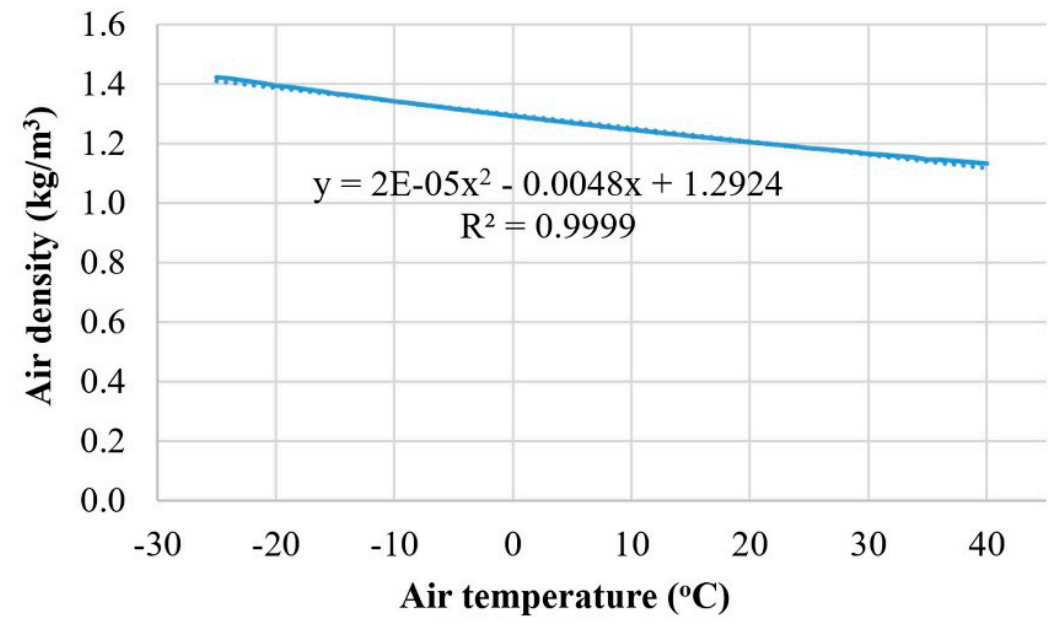

Figure 10. Air density versus the temperature under atmospheric pressure $1 \mathrm{~atm}$.

\subsection{Simulation Results of the VAV System}

\subsubsection{Cooling Load Coverage}

The coverage of the thermal zone 1 cooling load from:

- the fresh air flow required for the ventilation of the thermal zone 2 indoor space 
- the circulation air flow between thermal zones 1 and 2, for the concurrent coverage of the thermal zone 2 heating load

- the additional fresh air flow, beyond the thermal zone 2 ventilation requirements

- the introduced heat pump

as well as the total covered cooling power for thermal zone 1 are presented in Figure 11.

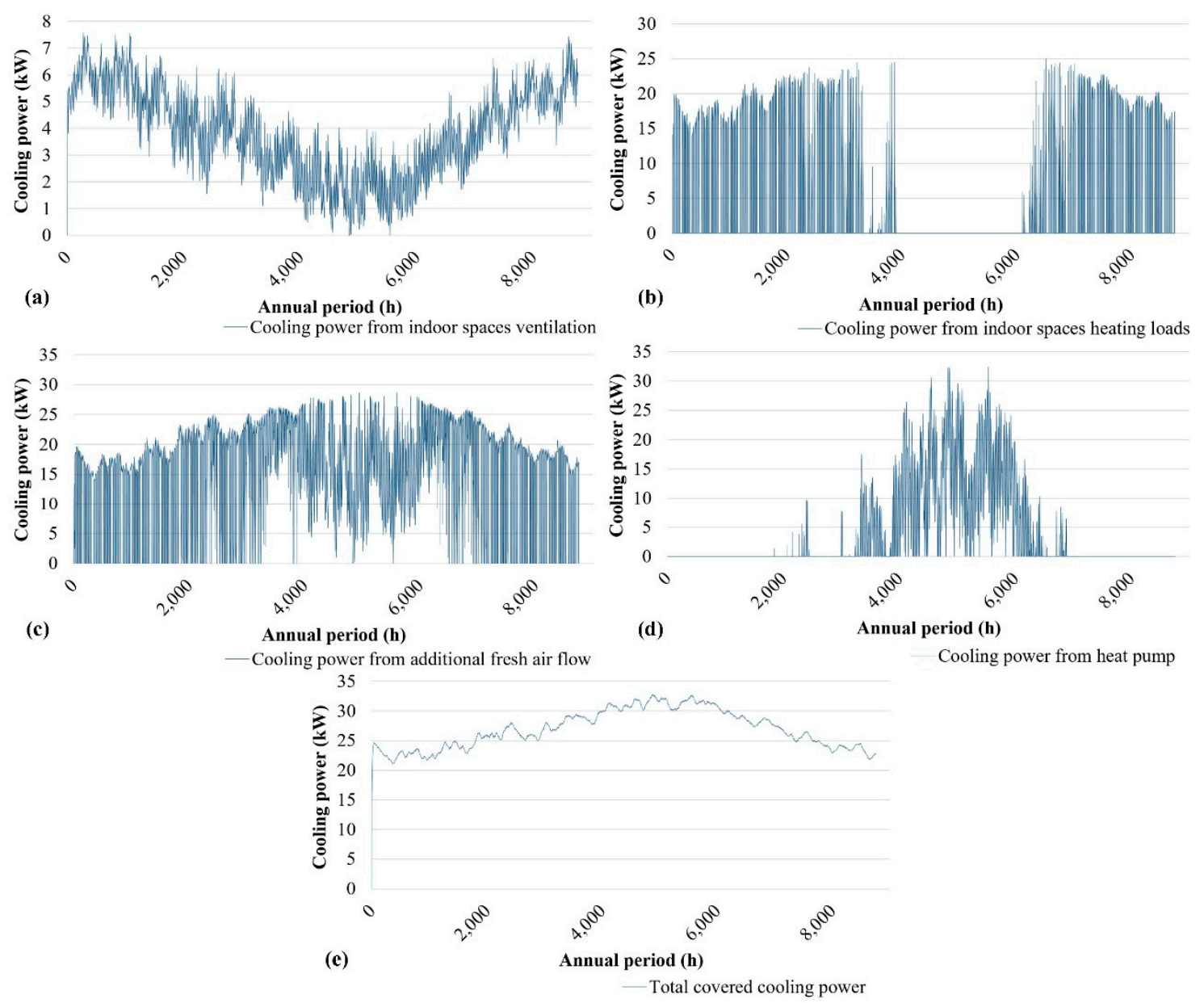

Figure 11. Annual time series of: (a) Cooling load coverage of thermal zone 1 from the fresh air flow required for indoor space ventilation in thermal zone 2; (b) the cooling load coverage of thermal zone 1 from the circulation air flow between thermal zones 1 and 2, for the simultaneous coverage of the thermal zone 2 heating load; (c) the cooling load coverage of thermal zone 1 from additional fresh air flow, beyond the ventilation requirements; (d) the cooling load coverage of thermal zone 1 from the heat pump; (e) the total cooling load coverage of thermal zone 1.

By observing Figure 11, we may conclude that the cooling load coverage from the fresh air flow reaches $100 \%$ during winter (Figure $11 \mathrm{a}, \mathrm{c}$ ). Additionally, the heat pump operation is restricted exclusively in summer period (Figure 11d). Finally, the cooling load coverage with the concurrent heating production for thermal zone 2 is eliminated in summer, obviously because of no heating load during this period (Figure 11b).

The monthly analysis of the presented time series is given in Table 5. In this table it is seen that the heat pump annual cooling production is restricted lower than $14 \%$ of the annual cooling demand, while the physical cooling undertakes the annual cooling production for more than $86 \%$. Additionally, more than $70 \%$ of the annual cooling demand is covered by the fresh air flow. Finally, the annual cooling coverage from the heating load is a bit less than $16 \%$. 
Table 5. Monthly analysis of the cooling load coverage in thermal zone 1.

\begin{tabular}{cccccc}
\hline \multirow{2}{*}{ Months } & \multicolumn{5}{c}{ Cooling Load Coverage (kWh) } \\
\cline { 2 - 6 } & Ventilation & Heating Load & Fresh Air & Heat Pump & Total \\
\hline January & 4.346 & 4.541 & 7.941 & 0 & 16.829 \\
February & 3.762 & 4.250 & 7.452 & 0 & 15.464 \\
March & 3.444 & 5.251 & 9.747 & 10 & 18.451 \\
April & 2.925 & 4.288 & 11.510 & 155 & 18.878 \\
May & 2.362 & 2.321 & 14.409 & 1.567 & 20.659 \\
June & 1.800 & 534 & 14.098 & 4.880 & 21.312 \\
July & 1.197 & 0 & 10.508 & 11.685 & 23.390 \\
August & 1.332 & 0 & 11.646 & 10.346 & 23.323 \\
September & 1.901 & 828 & 14.934 & 3.805 & 21.468 \\
October & 2.727 & 4.398 & 13.092 & 223 & 20.441 \\
November & 3.549 & 5.234 & 9.183 & 0 & 17.967 \\
December & 4.084 & 4.702 & 8.638 & 0 & 17.425 \\
Annual totals & 33.430 & 36.347 & 133.158 & 32.672 & 235.607 \\
Percentage contribution $(\%)$ & 14.19 & 15.43 & 56.52 & 13.87 & 100.00 \\
\hline
\end{tabular}

\subsubsection{Heating Load Coverage}

The coverage of the thermal zone 2 heating load from:

- the heat recovery from the cooling load coverage of thermal zone 1 from the fresh air flow required for the ventilation of thermal zone 2

- the heat recovery from the cooling load coverage of thermal zone 1 from the circulation air flow between thermal zones 1 and 2, for the concurrent coverage of the thermal zone 1 cooling load

- the heat recovery from the cooling load coverage of thermal zone 1 from the additional fresh air flow, beyond the thermal zone 2 ventilation requirements

- $\quad$ the introduced heat pump

as well as the total covered and uncovered heating load for thermal zone 2 are presented in Figure 12.

By observing Figure 12, we may conclude that the heating load coverage from the fresh air flows remains in low levels (Figure 12a,c), while the heating load coverage from the air circulation between thermal zones 1 and 2 reaches higher percentages (Figure 12b).

The monthly analysis of the presented time series is given in Table 6 . In this table, it is seen that the heat pump heating production is restricted at $40 \%$. Additionally, $60 \%$ of the annual heating needs in thermal zone 2 are covered with heat recovery. More precisely, $49 \%$ of the heating load is covered by the air circulation flows between thermal zones 1 and 2, verifying the efficiency of the proposed operation algorithm.

Due to the dimensioning of the heat pump versus the cooling load of thermal zone 1 and not versus the heating load of thermal zone 2, the annual heating load cannot be completely covered. Yet, only $3.8 \%$ of the annual heating load remains uncovered. 

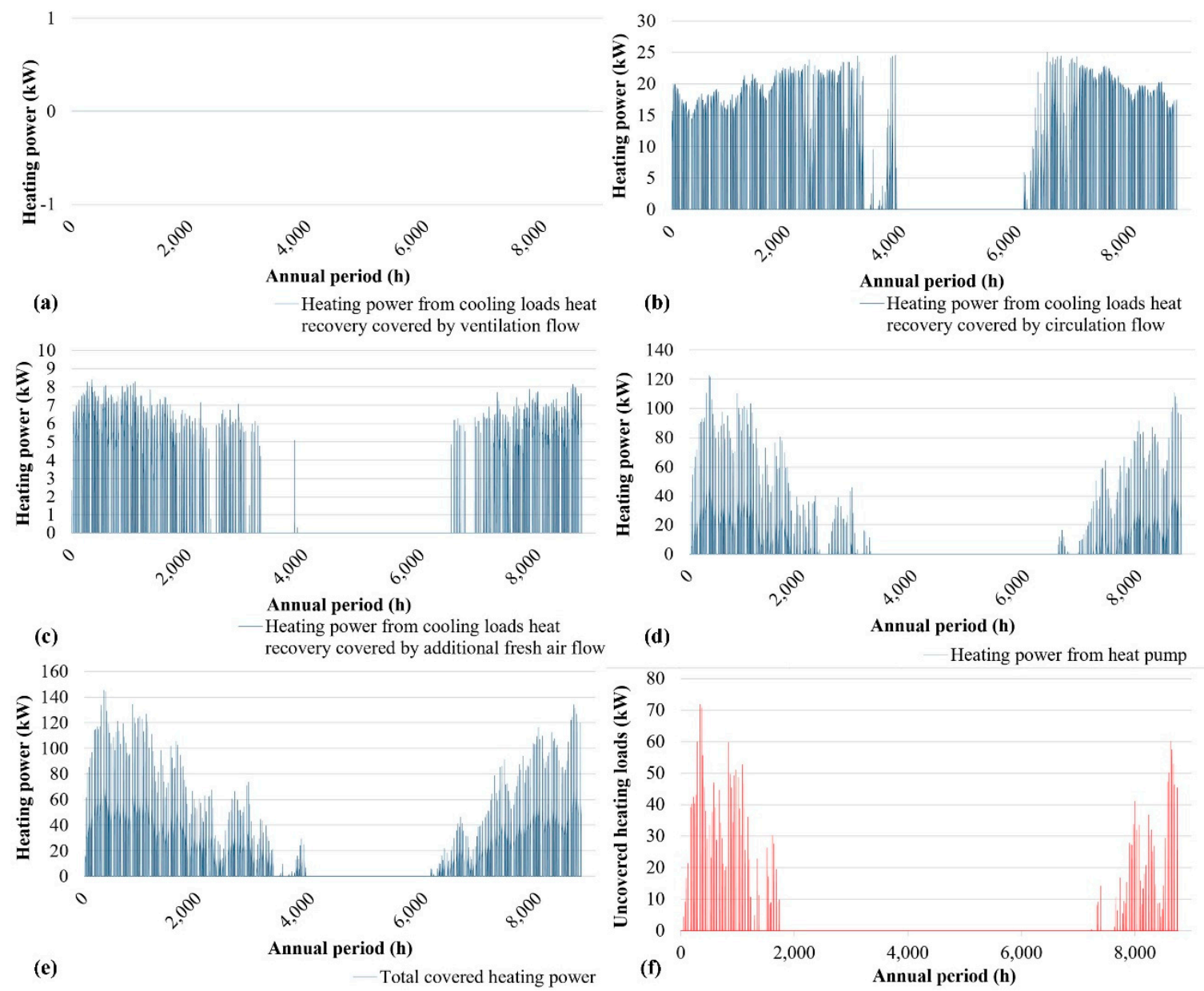

Figure 12. Annual time series of (a) the heating coverage of thermal zone 2 from the heat recovery from the cooling load coverage of thermal zone 1 from the fresh air flow required for indoor space ventilation; (b) the heating coverage of thermal zone 2 from the heat recovery from the air circulation flow between thermal zones 1 and 2, for the simultaneous cooling load coverage of thermal zone 1; (c) the heating coverage of thermal zone 2 from the heat recovery from the cooling load coverage of thermal zone 1 from additional fresh air flow, beyond the ventilation requirements; (d) the heating coverage of thermal zone 2 from the heat pump; (e) the total heating coverage of thermal zone 2; (f) the total uncovered heating load of thermal zone 2.

Table 6. Monthly analysis of the heating load coverage in thermal zone 2.

\begin{tabular}{|c|c|c|c|c|c|c|c|}
\hline \multirow[b]{2}{*}{ Months } & \multicolumn{7}{|c|}{ Heating Load Coverage (kWh) } \\
\hline & Ventilation & Circulation & $\begin{array}{l}\text { Fresh Air } \\
\text { Recovery }\end{array}$ & $\begin{array}{c}\text { Remaining } \\
\text { Load }\end{array}$ & Heat Pump & $\begin{array}{c}\text { Uncovered } \\
\text { Load }\end{array}$ & Total \\
\hline January & 0 & 4.541 & 1.686 & 8.198 & 7.252 & 946 & 14.425 \\
\hline February & 0 & 4.250 & 1.439 & 6.464 & 5.763 & 702 & 12.154 \\
\hline March & 0 & 5.251 & 1.024 & 2.769 & 2.612 & 157 & 9.044 \\
\hline April & 0 & 4.288 & 468 & 641 & 641 & 0 & 5.397 \\
\hline May & 0 & 2.321 & 125 & 177 & 177 & 0 & 2.623 \\
\hline June & 0 & 534 & 5 & 0 & 0 & 0 & 540 \\
\hline July & 0 & 0 & 0 & 0 & 0 & 0 & 0 \\
\hline August & 0 & 0 & 0 & 0 & 0 & 0 & 0 \\
\hline September & 0 & 828 & 5 & 0 & 0 & 0 & 833 \\
\hline October & 0 & 4.398 & 325 & 440 & 439 & 0 & 5.163 \\
\hline November & 0 & 5.234 & 1.403 & 3.919 & 3.656 & 263 & 10.556 \\
\hline December & 0 & 4.702 & 1.582 & 7.078 & 6.338 & 740 & 13.362 \\
\hline Annual totals & 0 & 36.347 & 8.063 & 29.685 & 26.877 & 2.808 & 74.095 \\
\hline $\begin{array}{c}\text { Percentage } \\
\text { contribution (\%) }\end{array}$ & 0.00 & 49.05 & 10.88 & 40.06 & 36.27 & 3.79 & 100.00 \\
\hline
\end{tabular}




\subsubsection{Electricity Consumption for Air Conditioning}

The electricity consumption from the heat pump for the thermal zone 2 heating and the thermal zone 1 cooling is simply calculated with the annual ambient temperature time series and by introducing the coefficient of performance (COP) and the energy efficiency ratio (EER) curves for the proposed heat pump versus the ambient temperature. Both of them are presented in Figure 13. The calculation is straightforward. The annual electricity consumption time series for cooling and heating is presented in Figure 14. The same time series is monthly analyzed in Table 7.
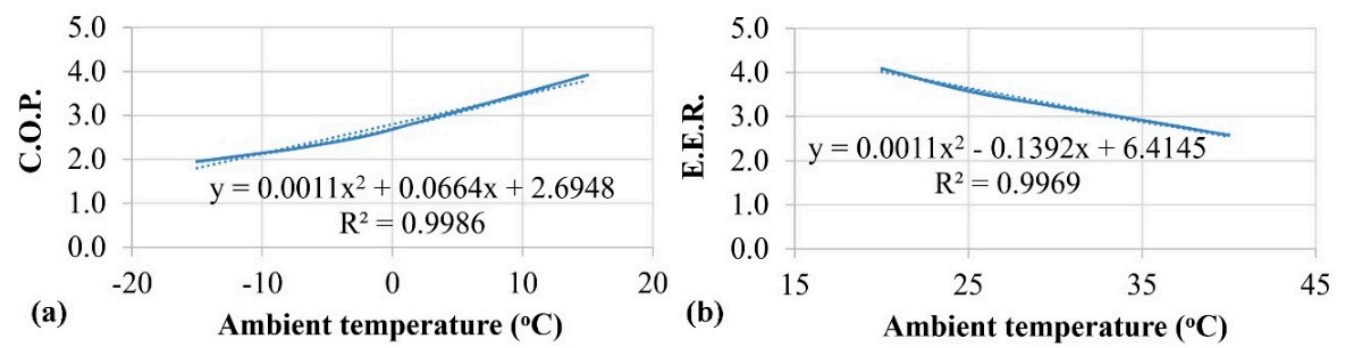

Figure 13. Fluctuation of (a) coefficient of performance (COP) and (b) energy efficiency ratio (EER) of the introduced VAV heat pump versus the ambient temperature.

$$
25
$$

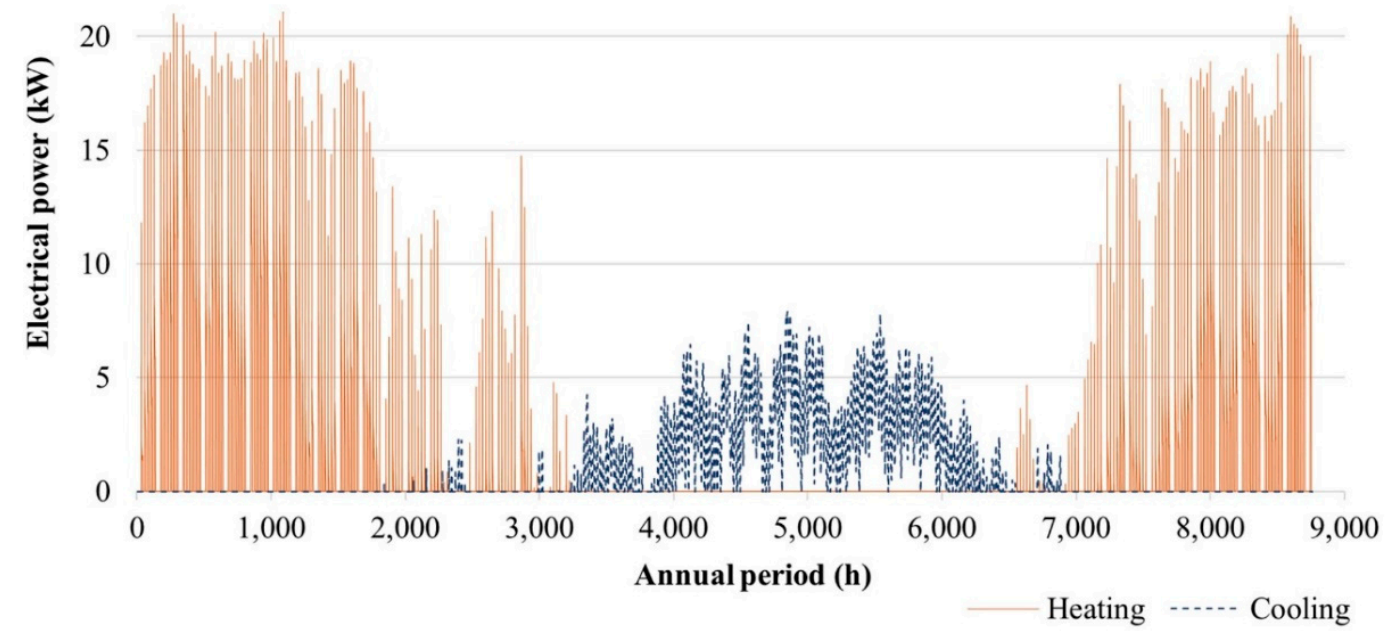

Figure 14. Annual fluctuation of electricity consumption from the heat pump for (a) the cooling of thermal zone 1 and (b) the heating of thermal zone 2. 
Table 7. Monthly analysis of the electricity consumption from the VAV heat pump for the heating of thermal zone 2 and the cooling of thermal zone 1.

\begin{tabular}{ccccccc}
\hline \multirow{2}{*}{ Month } & \multicolumn{2}{c}{ Electricity Peaks (kW) } & \multicolumn{2}{c}{ Electricity Consumption (kWh) } & \multicolumn{2}{c}{ Average Efficiency } \\
\cline { 2 - 7 } & Heating & Cooling & Heating & Cooling & C.O.P. & E.E.R. \\
\hline January & 20.5 & 0.0 & 2529.5 & 0.0 & 2.87 & - \\
February & 20.5 & 0.0 & 1956.4 & 0.0 & 2.95 & - \\
March & 18.9 & 1.0 & 842.2 & 2.5 & 3.10 & 4.09 \\
April & 14.7 & 2.3 & 197.9 & 37.0 & 3.24 & 4.19 \\
May & 12.5 & 4.2 & 48.3 & 375.2 & 3.66 & 4.18 \\
June & 0.0 & 6.4 & 0.0 & 1171.5 & - & 4.17 \\
July & 0.0 & 7.9 & 0.0 & 2815.5 & - & 4.15 \\
August & 0.0 & 7.8 & 0.0 & 2487.3 & - & 4.16 \\
September & 0.0 & 5.9 & 0.0 & 910.5 & - & 4.17 \\
October & 14.6 & 2.0 & 128.2 & 54.5 & 3.43 & 4.10 \\
November & 18.6 & 0.0 & 1174.2 & 0.0 & 3.11 & - \\
December & 20.4 & 0.0 & 2122.1 & 0.0 & 2.99 & - \\
Annual & 20.5 & 7.9 & 8998.7 & 7853.9 & 2.99 & 4.16 \\
\hline \multicolumn{2}{c}{ Total electricity consumption } & \multicolumn{7}{c}{$16,852.6$} \\
\hline
\end{tabular}

\subsubsection{Cooling of Thermal Zone 2}

In this last section of the computational simulation of the VAV system, the possibility for the cooling of the thermal zone 2 indoor space is investigated. Given the annual cooling load time series for the thermal zone 2 (Figure 3) and the EER fluctuation versus the ambient air temperature of the proposed heat pump (Figure 13), the annual electricity consumption time series from the heat pump for the thermal zone 2 cooling is calculated. It is presented in Figure 15.

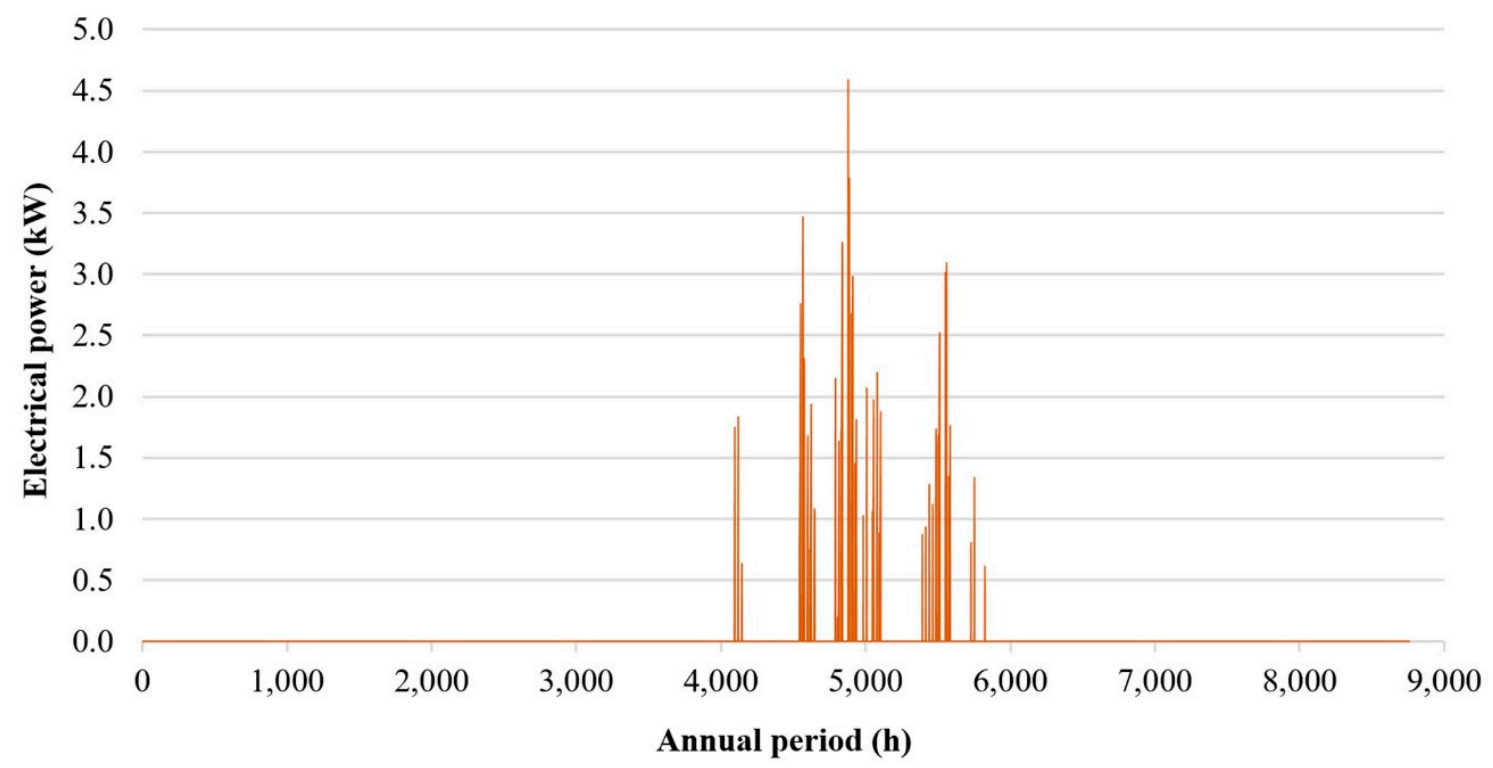

Figure 15. Annual fluctuation of the electricity consumption from the heat pump for the thermal zone 2 cooling.

Finally, the monthly analysis of the thermal zone 2 cooling load and the corresponding electricity consumption for its coverage is given in Table 8. 
Table 8. Electricity consumption from the heat pump for the thermal zone 2 cooling.

\begin{tabular}{ccccc}
\hline \multirow{2}{*}{ Month } & \multirow{2}{*}{$\begin{array}{c}\text { Cooling Load } \\
(\mathbf{k W h})\end{array}$} & \multicolumn{2}{c}{ Electricity Consumption } & Average E.E.R. \\
\cline { 3 - 4 } & & Peak Demand (kW) & Consumption (kWh) & \\
\hline January & 0.0 & 0.0 & 0.0 & - \\
February & 0.0 & 0.0 & 0.0 & - \\
March & 0.0 & 0.0 & 0.0 & - \\
April & 0.0 & 0.0 & 0.0 & - \\
May & 0.0 & 0.0 & 0.0 & - \\
June & 32.9 & 1.8 & 8.0 & 4.10 \\
July & 718.3 & 4.5 & 173.6 & 4.12 \\
August & 311.5 & 3.1 & 75.6 & - \\
September & 0.0 & 0.0 & 0.0 & - \\
October & 0.0 & 0.0 & 0.0 & - \\
November & 0.0 & 0.0 & 0.0 & - \\
December & 0.0 & 0.0 & 0.0 & 4.13 \\
Annual & 1062.7 & 4.5 & 257.2 & \\
\hline
\end{tabular}

\subsection{Simulation Results of the VRV System}

Following the presented operation algorithm of the VRV system, the cooling load is totally covered exclusively by the heat pump, namely no physical cooling is executed. This implies that the annual cooling production from the VRV system coincides with the annual cooling load time series, presented in Figure 3.

The annual heating load coverage of thermal zone 2, achieved with the heat recovery from the thermal zone 1 cooling process is presented in Figure 16a. The annual fluctuation of the uncovered heating load is presented in Figure 16b.
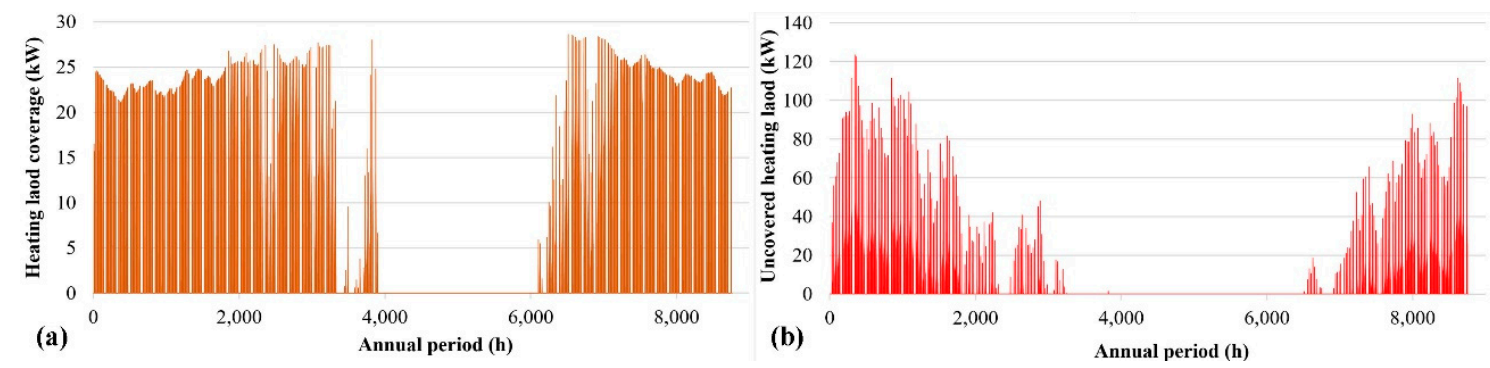

Figure 16. Annual fluctuation of (a) the thermal zone 2 heating load coverage from the heat recovery from the cooling load coverage of thermal zone 1 and (b) of the thermal zone 2 uncovered heating load.

The electricity consumption from the heat pump is simply calculated by introducing the EER curve of the VRV heat pump versus the ambient temperature. This curve is presented in Figure 17.

Eventually, from the EER curve and the ambient temperature annual time series (Figure 1), the electricity consumption annual time series from the heat pump for the cooling of thermal zone 1 is calculated. It is presented in Figure 18.

In Table 9, the monthly analysis of the heating and cooling load coverage and the corresponding electricity consumption with the VRV system are presented. 


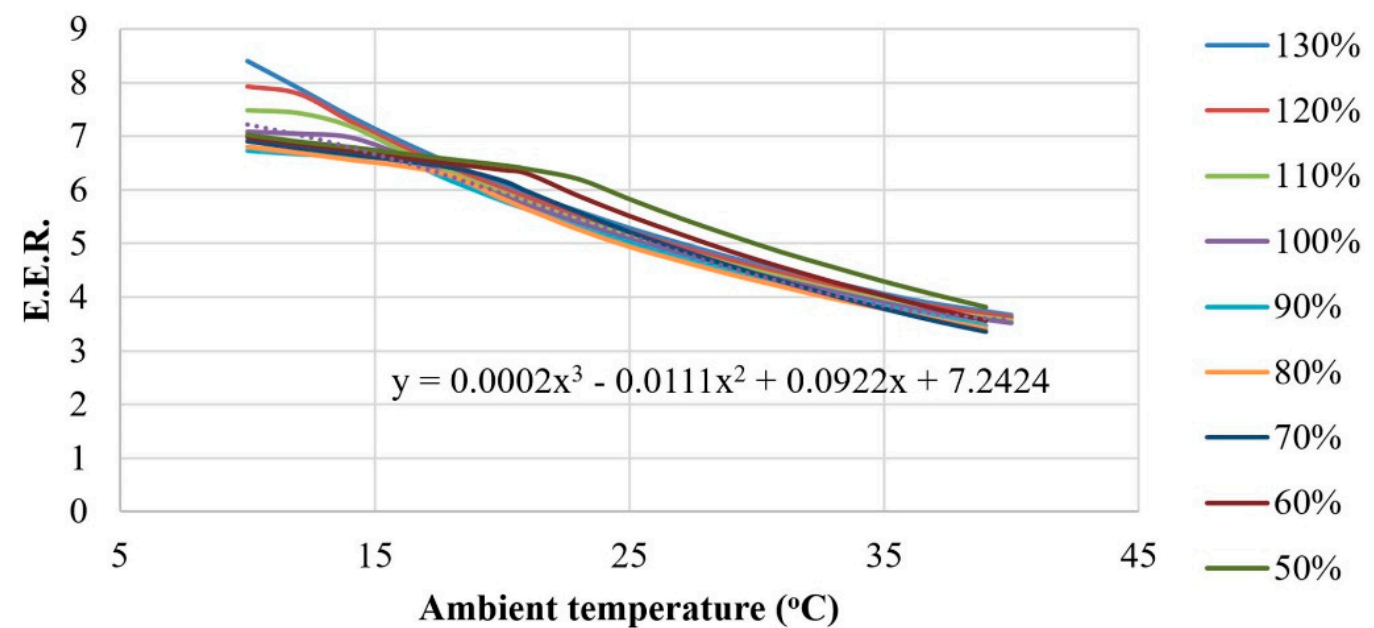

Figure 17. The EER fluctuation versus the ambient temperature of the VRV heat pump for various operation points versus the nominal cooling capacity.

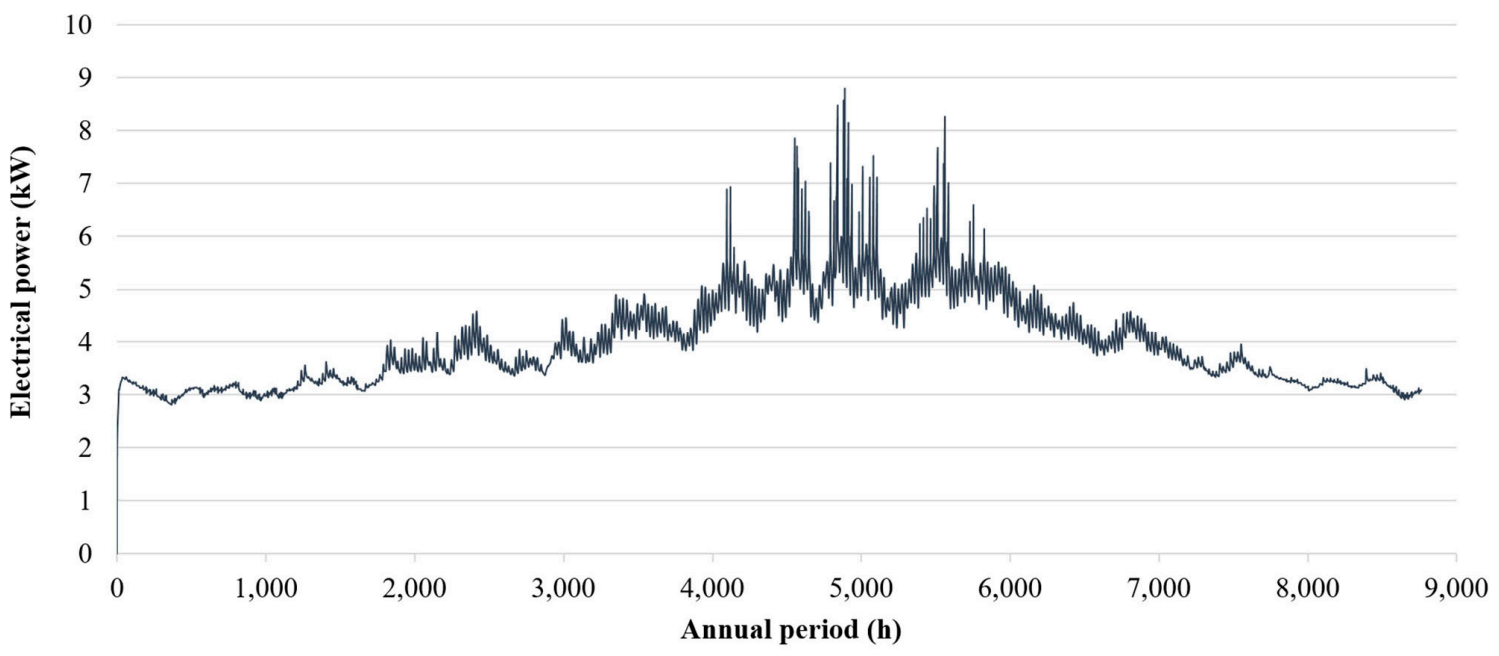

Figure 18. Annual fluctuation of the electricity consumption for the cooling load coverage of thermal zone 1 with the VRV heat pump.

Table 9. Monthly analysis of the heating and cooling load coverage and the corresponding electricity consumption with the VRV system.

\begin{tabular}{cccccc}
\hline \multirow{2}{*}{ Month } & \multicolumn{2}{c}{ Heating and Cooling Coverage } & \multicolumn{2}{c}{ Electricity Consumption for Cooling } \\
\cline { 2 - 5 } & Heating & Cooling & Peaks (kW) & Consumption (kWh) & E.E.R. \\
\hline January & 6029.8 & $16,851.9$ & 3.3 & 2273.5 & 7.41 \\
February & 5512.5 & $15,466.0$ & 3.6 & 2093.6 & 7.39 \\
March & 6172.4 & $18,452.9$ & 4.2 & 2548.0 & 7.24 \\
April & 4683.2 & $18,876.8$ & 4.6 & 2654.8 & 7.11 \\
May & 2411.6 & $20,663.2$ & 4.9 & 3054.6 & 6.76 \\
June & 538.4 & $21,346.3$ & 6.9 & 3314.8 & 6.44 \\
July & 0.0 & $24,110.5$ & 8.8 & 4010.4 & 6.01 \\
August & 0.0 & $23,634.2$ & 8.2 & 3876.6 & 6.10 \\
September & 831.3 & $21,464.4$ & 5.5 & 3295.8 & 6.51 \\
October & 4653.3 & $20,438.5$ & 4.6 & 2923.4 & 6.99 \\
November & 6412.7 & $17,963.6$ & 3.9 & 2447.9 & 7.34 \\
December & 6083.2 & $17,401.5$ & 3.5 & 2349.0 & 7.41 \\
Annual & $43,328.3$ & $236,669.9$ & 8.8 & $34,842.3$ & 6.79 \\
Percentage of annual & 58.48 & 100.00 & & & \\
load coverage $(\%)$ & & & & & \\
\hline
\end{tabular}




\section{Economic Figures}

In this section the set-up and operation cost of the two alternative proposed systems are presented. The set-up cost estimation for both systems is based on real quotations provided by the manufacturers of the main equipment. The operation cost is limited on the estimation of the electricity consumption cost from the heat pumps (maintenance cost is neglected).

In Tables 10 and 11, the set-up cost for the VAV and the VRV conditioning systems are presented, respectively.

Table 10. Set-up cost of the VAV system.

\begin{tabular}{cccc}
\hline Description & Quantity & Unit Cost (€) & Subtotal (€) \\
\hline D-AHU professional $6000 \mathrm{~m}^{3} / \mathrm{h} 50 \mathrm{~kW}$ & 2 & 13,000 & 26,000 \\
D-AHU assembly & 2 & 1500 & 3000 \\
Heat pump & 1 & 20,845 & 20,845 \\
Start-up and configuration of heat pump & 1 & 600 & 600 \\
Insulated air-ducts (indicative cost) & 1 & 20,000 & 20,000 \\
BMS (indicative cost) & 1 & 10,000 & 10,000 \\
& Total: & & 80,445 \\
\hline
\end{tabular}

Table 11. Set-up cost of the VRV system.

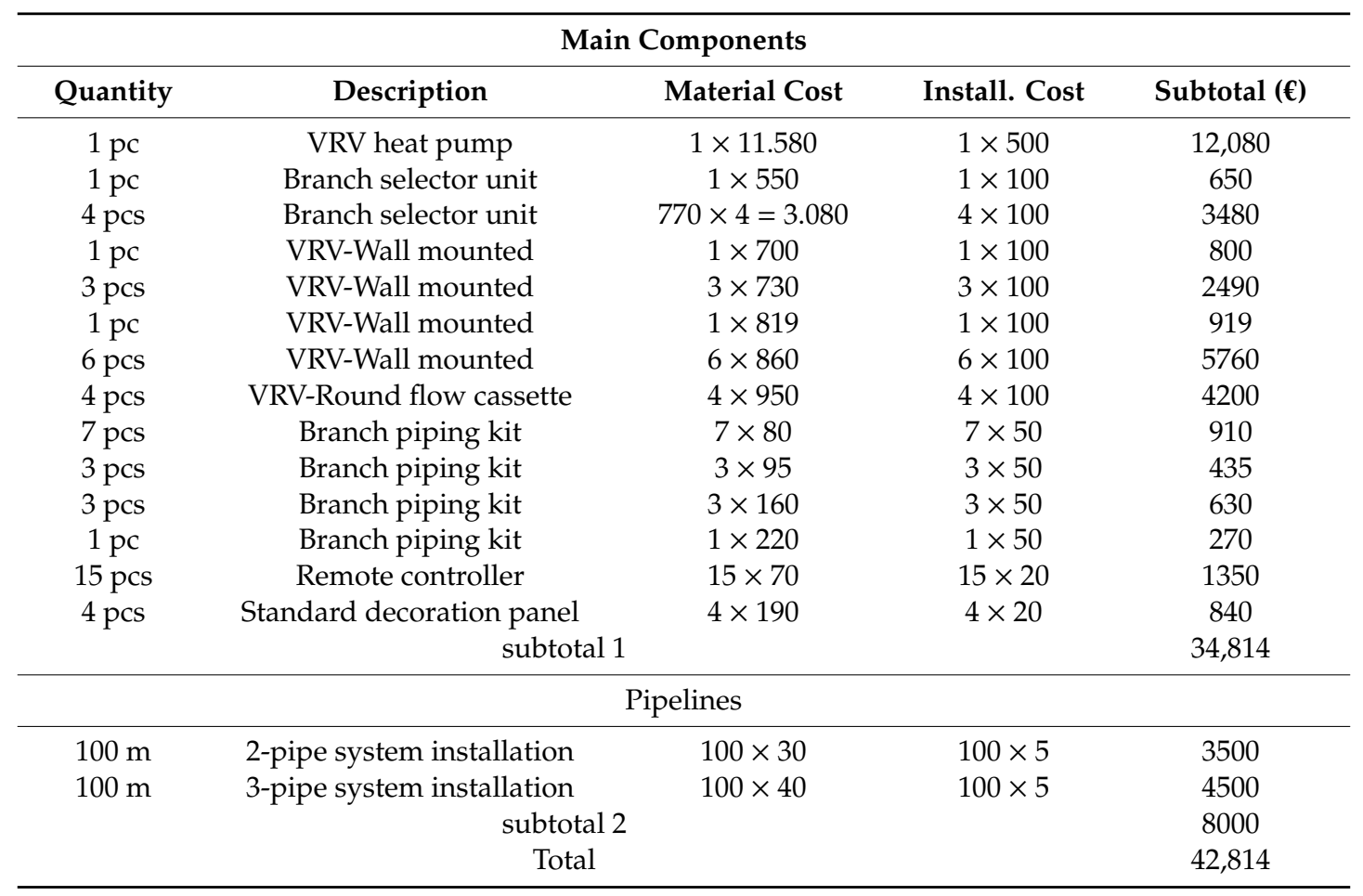

In Table 12, the annual operation cost is estimated, based on the electricity procurement price for the AEM, introduced equal to $0.069 € / \mathrm{kWh}$ (all costs included). At the same table, the annual operation costs of the two alternative systems are compared between them. A payback time period is calculated for the additional set-up cost of the more expensive system (VAV), namely the set-up cost difference between the VAV and the VRV system $(80,445-42,814=37,631 €)$, versus the annual economic benefit from its reduced operation cost, compared to the VRV system. 
Table 12. Operation cost of the proposed system.

\begin{tabular}{|c|c|c|c|c|c|}
\hline \multirow[b]{2}{*}{ System } & \multirow[b]{2}{*}{ Set-up Cost (€) } & \multicolumn{4}{|c|}{ Only Cooling } \\
\hline & & $\begin{array}{l}\text { Annual Electricity } \\
\text { Consumption } \\
(\mathbf{k W h})\end{array}$ & $\begin{array}{l}\text { Electricity } \\
\text { Procurement } \\
\text { Cost (€) }\end{array}$ & $\begin{array}{l}\text { Annual Monetary } \\
\text { Saving (€) }\end{array}$ & $\begin{array}{l}\text { VAV Additional } \\
\text { Set-up Cost Payback } \\
\text { Period (years) }\end{array}$ \\
\hline VAV & 80,445 & 7854 & 542 & 1862 & 20.2 \\
\hline VRV & 42,814 & 34,842 & 2404 & & \\
\hline \multirow[b]{2}{*}{ System } & \multirow[b]{2}{*}{ Set-up cost $(\boldsymbol{\epsilon})$} & \multicolumn{4}{|c|}{ Cooling \& heating } \\
\hline & & $\begin{array}{l}\text { Annual electricity } \\
\text { consumption (kWh) }\end{array}$ & $\begin{array}{l}\text { Electricity } \\
\text { procurement } \\
\text { cost }(\epsilon)\end{array}$ & $\begin{array}{l}\text { Annual monetary } \\
\text { saving }(\boldsymbol{\epsilon})\end{array}$ & $\begin{array}{l}\text { VAV additional } \\
\text { set-up cost payback } \\
\text { period (years) }\end{array}$ \\
\hline VAV & 80,445 & 16,853 & 1163 & 1241 & 30.3 \\
\hline VRV & 42,814 & 34,842 & 2404 & & \\
\hline
\end{tabular}

The systems are compared between them under two alternative bases:

- Firstly, by taking into account only the cooling operation, since the VRV is practically restricted to this. We can say that with this approach the two systems are compared on a common basis.

- Secondly, by taking into account both the heating and the cooling operation. This approach is not based on the same results, since, the VAV system is capable, due to its flexible and sophisticated operation, to cover almost $97 \%$ of the annual heating load, while the VRV covers only $58 \%$ of the annual heating load.

The relatively long payback periods presented in Table 12 certainly constitute a discouraging decision parameter for the selection of the VAV system.

\section{Comparison of the Investigated Systems}

Following the results of the above energetic and economic calculations, under a comparative analysis of the investigated systems, we may conclude that the main advantages of the VAV system come from its high operation flexibility. More specifically, by following the newly introduced operation algorithm, $86 \%$ of the annual cooling load coverage is based on physical cooling, while the $60 \%$ of the annual heating load is covered exclusively with heat recovery. The above sensibly lead to the minimisation of the annual electricity consumption for the indoor space conditioning and the corresponding minimisation of the annual operation cost.

On the other hand, the main disadvantages of the VAV system are of a constructive nature, such as the increased space requirements for its installation in the building, the more complex installation, the noisier operation due to the heating and cooling supply through the air-ducts networks and the heat losses through the same heating and cooling distribution network [33]. Additionally, the involved outdoor air-to-air heat pump exhibits lower EER and COP than a VRV heat pump, yet compensated due to its restricted operation. Additionally, the realization of the proposed algorithm requires an external control system, which increases the set-up cost and makes the whole system more complicated. Finally, the VAV exhibits higher set-up cost than the VRV system.

The main advantages of the VRV system are the lower set-up cost, the minimization of the required installation space, the compact and more elegant installation and the higher EER and COP of the air-to-water heat pump, which, up to an extent, compensate the increased electricity consumption. Additionally, heat recovery is also available with the same heat pump, without the necessity of any additional complicated systems.

The main disadvantage of the VRV system is the reduced operation flexibility (no physical cooling can be performed), leading to higher electricity consumption and, subsequently, operation cost. Another direct result coming from the restricted operation flexibility is the reduced annual coverage of the heating load, reaching only $58.5 \%$. This imposes the requirement for another active system for the coverage of the considerable remaining heating load. 
On the question of which one of the investigated systems is the optimum one for the specific facility, obviously there is not any definite answer. The final choice depends on the above decision parameters and their impact factors, according to the requirements of the hydro power plant's owner. For example, if the reduction of the system's set-up cost, the noiseless operation of the cooling system and the minimisation of the occupied space constitute crucial factors, then the VRV system should be selected. If, on the other hand, the minimisation of the cooling system's operation cost and the consumed primary energy resources is the main objective, then the VAV system should be selected.

\section{Conclusions}

This article focuses on the computational analysis of the operation of the VAV and VRV systems, aiming at the maximisation of the cooling and heating load coverage with physical cooling and heat recovery. The ultimate scope of this article was to highlight the high energy saving potential that can be achieved with the exploitation of these processes. To this end, a new operation algorithm was introduced, particularly for the VAV system, given its higher flexibility for physical cooling and heat recovery. In this way, a standardization was introduced on the operation of the VAV systems with extensive implementation of physical cooling and heat recovery processes.

The introduced operation algorithm was evaluated through its computational simulation and its application on a specific case study. It was eventually shown that high electricity saving percentages can be achieved on the heating and cooling needs coverage through the implementation of physical cooling and heat recovery implemented by the VAV systems. For example, in the case of the under consideration case study, $86 \%$ of the annual cooling needs was covered with physical cooling and $60 \%$ of the annual heating needs was covered with heat recovery.

A crucial parameter, however, for the achievement of such high energy saving percentages, is the existence of favorable operation conditions. These conditions were formulated in the executed case study due to the significant cooling load even during winter, a fact that enabled both the coverage of this cooling load with the operation of the VAV system under the economizer mode and the coverage of the concurrent heating load through the disposed heat recovery from the cooling process.

The above conditions are necessary for the application of the proposed algorithm, given that it focuses on the optimization of physical cooling and heat recovery processes. Indeed, it is sensible that physical cooling can be applied when the ambient temperature is lower than the required indoor temperature. This implies that there must be a cooling load even during cold periods of the year. Practically this can happen in the case of important internal heat gains or solar gains through transparent surfaces. The existence of the cooling load during cold seasons also creates the potential for concurrent heating load coverage for other thermal zones in the building, via heat recovery, exploiting the disposed heat with the cooling process. It is conceivable that, since the proposed algorithm focuses on the optimisation of concurrent physical cooling and heat recovery processes, its application under different circumstances may not have any sense, or, in other words, could not be applicable. The particular conditions, yet, can be met in a variety of buildings and premises, such as industries, gyms, hospitals, conference halls, theatres and cinemas, buildings with significant solar gains on specific zones (e.g., bioclimatic buildings with integrated solar rooms), etc.

All these maximise the potential applicability of the presented system's layout along with its operation algorithm. Indeed, the VAV operation algorithm introduced in this article is easily applied in any case of indoor space conditioning with similar operation conditions, maybe with adaptations and modifications relevant to the specific needs and operation requirements for each different case. Depending on these parameters, the potential energy saving percentages may vary but they should also remain within high values. Another critical issue, not examined in the present study, is the adequate application of the proposed algorithm through an automatic management system, which, practically, constitutes a fundamental prerequisite for the achievement of the anticipated energy saving percentage.

A VRV system was also introduced and examined for comparison reasons, for the coverage of the concurrent cooling and heating load, the latter exclusively with heat recovery, with a simple operation 
algorithm, giving priority to the cooling load coverage. The size and the time coincidence of the cooling and heating load enabled $58 \%$ coverage of the annual heating load with heat recovery. The operation concept and the technology of the VRV systems implies less flexibility and options for further energy saving either for the cooling or the heating load coverage.

The higher VAV set-up cost, compared to the VRV systems, seems to constitute a negative decision parameter, yet, in the cases of already existing air-duct distribution networks, which actually is a reality for a large amount of commercial and public buildings, this drawback is weaved, since one of the main set-up cost components (installation of the air-ducts network) is eliminated.

Summarizing, the high energy saving potential was highlighted in this article through the appropriate operation of both the VAV and VRV systems and the extensive implementation of physical cooling and heat recovery.

The proposed algorithm and system's layout would be interesting to be applied in different buildings and premises with a similar operation, perhaps with slight modifications, depending exactly on the particularly met conditions and requirements (e.g., a sports centre, a conference or a cultural hall, a hospital or other types of industries). In this way, the applicability and the effectiveness of the proposed algorithm could be examined in alternative cases. Finally, it would be also highly interesting, if AEM selects to install the examined VAV system in the specific hydro power plant, to proceed to the execution of measurements on the operation of the installed system, with which, after the required processing, the effectiveness of the proposed algorithm and the accuracy of the executed calculation results can be confirmed.

Author Contributions: Conceptualization, D.K. and V.K.; Methodology, D.K.; Software, D.K.; Validation, D.K. and V.K.; Formal analysis, D.K.; Investigation, D.K. and V.K.; Resources, G.Z. and L.A.; Data curation, G.Z. and L.A.; Writing—original draft preparation, D.K.; Writing—review and editing, D.K.; Visualization, D.K.; Supervision, D.K.; Project administration, L.A.; Funding acquisition, L.A.

Funding: This research was funded by AZIENDA ELETTRICA DI MASSAGNO S.A.

Acknowledgments: Special thanks to Paolo Rossi, Director of Azienda Elettrica di Massagno S.A., for the assignment of this work.

Conflicts of Interest: The authors declare no conflict of interest.

\section{References}

1. Ye, Y.; Li, W. Energy analysis on VAV system with different air-side economizers in China. Energy Build. 2010, 42, 1220-1230.

2. Nassif, N.; Moujaes, S. A new operating strategy for economizer dampers of VAV system. Energy Build. 2008, 40, 289-299. [CrossRef]

3. Jeong, E.S.; Kwang, H.L. Cooling energy performance analysis depending on the economizer cycle control methods in an office building. Energy Build. 2016, 120, 45-57.

4. Kim, H.J.; Cho, Y.H. A Study on a Control Method with a Ventilation Requirement of a VAV System in Multi-Zone. Sustainability 2017, 9, 2066. [CrossRef]

5. Godwine, S.O.; Ye, Y. A review of recent developments and technological advancements of variable-air-volume (VAV) air-conditioning systems. Renew. Sustain. Energy Rev. 2016, 59, 784-817.

6. Aynur, N.T.; Hwang, Y.; Radermacher, R. Simulation comparison of VAV and VRF air conditioning systems in an existing building for the cooling season. Energy Build. 2009, 41, 1143-1150. [CrossRef]

7. Kim, D.; Cox, S.J.; Cho, H.; Im, P. Evaluation of energy savings potential of variable refrigerant flow (VRF) from variable air volume (VAV) in the U.S. climate locations. Energy Rep. 2017, 3, 85-93. [CrossRef]

8. Woolley, E.; Luo, Y.; Simeone, A. Industrial waste heat recovery: A systematic approach. Sustain. Energy Technol. Assess. 2018, 29, 50-59. [CrossRef]

9. Huang, F.; Zheng, J.; Baleynaud, J.M.; Lu, J. Heat recovery potentials and technologies in industrial zones. J. Energy Inst. 2017, 90, 951-961. [CrossRef] 
10. Papapetrou, M.; Kosmadakis, G.; Cipollina, A.; Commare, U.L.; Micale, G. Industrial waste heat: Estimation of the technically available resource in the EU per industrial sector, temperature level and country. Appl. Therm. Eng. 2018, 138, 207-216. [CrossRef]

11. Jouhara, H.; Khordehgah, N.; Almahmoud, S.; Delpech, B.; Chauhan, A.; Tassou, S.A. Waste heat recovery technologies and applications. Therm. Sci. Eng. Prog. 2018, 6, 268-289. [CrossRef]

12. Ziemele, J.; Kalnins, R.; Vigants, G.; Vigants, E.; Veidenbergs, I. Evaluation of the industrial waste heat potential for its recovery and integration into a fourth generation district heating system. Energy Procedia 2018, 147, 315-321. [CrossRef]

13. Ishaq, H.; Dincer, I.; Naterer, G.F. New trigeneration system integrated with desalination and industrial waste heat recovery for hydrogen production. Appl. Therm. Eng. 2018, 142, 767-778. [CrossRef]

14. Mukherjee, S.; Asthana, A.; Howarth, M.; Mcniell, R. Waste heat recovery from industrial baking ovens. Energy Procedia 2017, 123, 321-328. [CrossRef]

15. Pantaleo, A.M.; Fordham, J.; Oyewunmi, O.A.; Palma, R.D.; Markides, C.H. Integrating cogeneration and intermittent waste-heat recovery in food processing: Microturbines vs. ORC systems in the coffee roasting industry. Appl. Energy 2018, 225, 782-796. [CrossRef]

16. Naldi, C.; Dongellini, M.; Morini, G.L. Summer Performances of Reversible Air-to-water Heat Pumps with Heat Recovery for Domestic Hot Water Production. Energy Procedia 2015, 78, 1117-1122. [CrossRef]

17. Li, F.; Sun, B.; Zhang, C.; Zhang, L. Operation optimization for combined cooling, heating, and power system with condensation heat recovery. Appl. Energy 2018, 230, 305-316. [CrossRef]

18. Katsaprakakis, D.A. Comparison of swimming pools alternative passive and active heating systems based on renewable energy sources in Southern Europe. Energy 2015, 81, 738-753. [CrossRef]

19. Burlacu, A.; Sosoi, G.; Vizitiu, R.S.; Bărbuță, M.; Lăzărescu, C.D.; Verdeș, M.; Șerbănoiu, A.A. Innovative system for heat recovery from used water in the building sector. Procedia Manuf. 2018, 22, 722-729. [CrossRef]

20. Tanha, K.; Fung, A.S.; Kumar, R. Performance of two domestic solar water heaters with drain water heat recovery units: Simulation and experimental investigation. Appl. Therm. Eng. 2015, 90, 444-459. [CrossRef]

21. Abdel-Aal, M.; Schellart, A.; Kroll, S.; Mohamed, M.; Tait, S. Modelling the potential for multi-location in-sewer heat recovery at a city scale under different seasonal scenarios. Water Res. 2018, 145, 618-630. [CrossRef] [PubMed]

22. Rongpeng, Z.; Kaiyu, S.; Hong, T.; Yoshinori, Y.; Ryohei, H. A novel Variable Refrigerant Flow (VRF) heat recovery system model: Development and validation. Energy Build. 2018, 168, 399-412.

23. Lee, J.M.; Hong, S.H.; Seo, B.M.; Lee, K.H. Application of artificial neural networks for optimized AHU discharge air temperature set-point and minimized cooling energy in VAV system. Appl. Therm. Eng. 2019, 153, 726-738. [CrossRef]

24. Wang, J.; Wang, Y. Performance improvement of VAV air conditioning system through feedforward compensation decoupling and genetic algorithm. Appl. Therm. Eng. 2008, 28, 566-574. [CrossRef]

25. Nasruddin; Sholahudin; Satrio, P.; Mahlia, T.M.I.; Giannetti, G.; Saito, K. Optimization of HVAC system energy consumption in a building using artificial neural network and multi-objective genetic algorithm. Sustain. Energy Technol. Assess. 2019, 35, 48-57. [CrossRef]

26. Moon, J.W.; Yang, Y.K.; Choi, E.J.; Choi, Y.J.; Lee, K.H.; Kim, Y.S.; Park, B.R. Development of a control algorithm aiming at cost-effective operation of a VRF heating system. Appl. Therm. Eng. 2019, 149, 1522-1531. [CrossRef]

27. Federal Office of Meteorology and Climatology MeteoSwiss. Available online: https://www.meteoswiss. admin.ch/home/climate/swiss-climate-in-detail.html (accessed on 10 July 2019).

28. Katsaprakakis, D.; Moniakis, M. Heating, Cooling and Air Conditioning of Buildings, 1st ed.; Kallipos, Association of Greek Academic Libraries: Athens, Greece, 2015; Available online: http://hdl.handle.net/11419/6167 (accessed on 10 July 2019).

29. Kreider, J.; Rabl, A.; Curtiss, P. Heating and Cooling of Buildings, 3rd ed.; CRC Press: Boca Raton, FL, USA, 2017.

30. 2009 ASHRAE Handbook-Fundamentals (SI Edition); American Society of Heating, Refrigerating and Air-Conditioning Engineers, Inc.: Atlanta, GA, USA, 2009.

31. The Energy Standard and Label MINERGIE. Available online: https://www.minergie.ch/ (accessed on 12 July 2019). 
32. Psychrometrics. In 2009 ASHRAE Handbook-Fundamentals (SI Edition); American Society of Heating, Refrigerating and Air-Conditioning Engineers, Inc.: Atlanta, GA, USA, 2009; Chapter 6.

33. Krishnamoorthy, S.; Modera, M. Impacts of duct leakage on central outdoor-air conditioning for commercial-building VAV systems. Energy Build. 2016, 119, 340-351. [CrossRef]

(C) 2019 by the authors. Licensee MDPI, Basel, Switzerland. This article is an open access article distributed under the terms and conditions of the Creative Commons Attribution (CC BY) license (http://creativecommons.org/licenses/by/4.0/). 